\title{
Hydrogen Sulphide Treatment Prevents Renal Ischemia-Reperfusion Injury by Inhibiting the Expression of ICAM-1 and NF-kB Concentration in Normotensive and Hypertensive Rats
}

\author{
Syed F. Hashmi ${ }^{1,+}{ }^{\text {, Hassaan Anwer Rathore }}{ }^{1, t} \neq$, Munavvar A. Sattar ${ }^{1}$, Edward J. Johns ${ }^{2} \mathbb{D}$, Chee-Yuen Gan ${ }^{3} \mathbb{D}$, \\ Tan Yong Chia ${ }^{3, *(\mathbb{D})}$ and Ashfaq Ahmad 1,4,*(D) \\ 1 School of Pharmaceutical Sciences, Universiti Sains Malaysia, Penang 11800, Malaysia; \\ fayazhashmi84@gmail.com (S.F.H.); hrathore@qu.edu.qa (H.A.R.); munavvar@usm.my (M.A.S.) \\ 2 Department of Physiology, University College Cork, T12 K8AF Cork, Ireland; ej.johns@ucc.ie \\ 3 Analytical Biochemistry Research Centre (ABrC), Universiti Sains Malaysia (USM), Lebuh Bukit Jambul, \\ Penang 11900, Malaysia; cygan@usm.my \\ 4 Department of Pharmacy Practice, College of Pharmacy, University of Hafr Al-Batin, \\ Hafr Al-Batin 31991, Saudi Arabia \\ * Correspondence: tanyongchia@usm.my (T.Y.C.); ashfaqa@uhb.edu.sa (A.A.); Tel.: +966-504309874 (A.A.) \\ + These authors contributed equally to this work. \\ $\ddagger$ Current Address: College of Pharmacy, Qatar University, Doha P.O. Box 2713, Qatar.
}

Citation: Hashmi, S.F.; Rathore, H.A.; Sattar, M.A.; Johns, E.J.; Gan, C.-Y.; Chia, T.Y.; Ahmad, A. Hydrogen Sulphide Treatment Prevents Renal Ischemia-Reperfusion Injury by Inhibiting the Expression of ICAM-1 and NF-kB Concentration in Normotensive and Hypertensive Rats. Biomolecules 2021, 11, 1549. https:// doi.org/10.3390/biom11101549

Academic Editor: Csaba Szabo

Received: 2 October 2021

Accepted: 14 October 2021

Published: 19 October 2021

Corrected: 18 April 2022

Publisher's Note: MDPI stays neutral with regard to jurisdictional claims in published maps and institutional affiliations.

Copyright: (c) 2021 by the authors Licensee MDPI, Basel, Switzerland. This article is an open access article distributed under the terms and conditions of the Creative Commons Attribution (CC BY) license (https:/ / creativecommons.org/licenses/by/ $4.0 /)$.
Abstract: Our main objective was to investigate the effect of chronic administration of hydrogen sulphide donor (sodium hydrosulphide) on the expression of intercellular adhesion molecule-1 (ICAM-1) and concentration of nuclear factor-kappa B (NF-kB) in a renal ischemia-reperfusion injury (IRI) model of WKY and L-nitro-arginine-methyl-ester (L-NAME)-induced hypertensive rats. Sodium hydrosulphide (NaHS) was administered intraperitoneally (i.p.) for 35 days while cystathionine gamma lyase (CSE) inhibitor dL-propargylglycine (PAG) was administered at a single dose of $50 \mathrm{mg} / \mathrm{kg}$. Animals were anesthetised using sodium pentobarbitone $(60 \mathrm{mg} / \mathrm{kg})$ and then prepared to induce renal ischemia by clamping the left renal artery for $30 \mathrm{~min}$ followed by $3 \mathrm{~h}$ of reperfusion. Pre-treatment with NaHS improved the renal functional parameters in both WKY and L-NAMEinduced hypertensive rats along with reduction of blood pressure in hypertensive groups. Oxidative stress markers like malondialdehyde (MDA), total superoxide dismutase (T-SOD) and glutathione (GSH) were also improved by NaHS treatment following renal IRI. Levels of ICAM-1 and NF-kB concentration were reduced by chronic treatment with NaHS and increased by PAG administration after renal IRI in plasma and kidney. Treatment with NaHS improved tubular morphology and glomerulus hypertrophy. Pre-treatment with NaHS reduced the degree of renal IRI by potentiating its antioxidant and anti-inflammatory mechanism, as evidenced by decreased NF-kB concentration and downregulation of ICAM-1 expression.

Keywords: hydrogen sulphide; ischemia-reperfusion injury; L-nitro-arginine-methyl-ester; ICAM-1; NF-kB; PAG

\section{Introduction}

Ischemia-reperfusion injury (IRI) is a common cause of functional impairment of reperfused organs associated with increased production of reactive oxygen species (ROS). ROS during IRI induce initial inflammatory responses, which in turn results in the adhesion of leukocytes [1]. Leukocytes' adhesion, rolling and migration to the ischemic tissues, followed by reperfusion, is initiated by initial inflammatory responses [2]. The expression of ICAM-1 on the surface of leukocytes [3] and endothelium [4] plays an important role in potentiating the initiation of inflammatory responses [5], which are involved in the 
pathogenesis of post-ischemic organ damage. Transcription of ICAM-1 is dependent upon nuclear factor-kappa B (NF-kB) activation [6]. In non-stimulated cells, NF-kB lies in the cytoplasm in inactive form, along with inhibitory kappa B (IkB) inhibitors. Various stimuli cause the degradation of IkB. As a result of this degradation, NF-kB enters the nucleus where it induces the synthesis of its specific mRNA by binding to DNA. Expressions of different specific genes are controlled by the transcription factor NF-kB and, once this transcription factor is activated by any stimuli, it can enhance the severity of IRI [7]. ROS production causes the activation of NF-kB [8,9]. Once NF-kB is activated, it induces ICAM-1 expression [10]. However, ROS and inflammatory responses play key roles in the pathogenesis of IRI through NF-kB and the ICAM-1 pathway.

The failure of many renal transplantation procedures results from the consequences of IRI. Various treatment approaches have been investigated by targeting oxidative stress and inflammation in order to minimize the extent of IRI in laboratory animals. Treatments, including antioxidant therapies and ROS scavengers, like naringin [11] and catechin [12], have been reported to improve renal IRI. Keeping in view the importance of antioxidant and anti-inflammatory mechanisms in IRI, the present study chose exogenous hydrogen sulphide $\left(\mathrm{H}_{2} \mathrm{~S}\right)$ treatment because of its antioxidant $[13,14]$ and anti-inflammatory potential [15,16] and its hypo-metabolism-induced hypoxic environment [17].

$\mathrm{H}_{2} \mathrm{~S}$ is a physiologically active gasotransmitter. Endogenously, two enzymes, named cystathionine beta synthase (CBS) and cystathionine gamma lyase (CSE), are involved in the production of $\mathrm{H}_{2} \mathrm{~S}$ [18]. However, a third enzyme named 3-mercaptopyruvate sulphur transferase (3-MST) has also recently been reported to participate in the production of $\mathrm{H}_{2} \mathrm{~S}$ [19]. CSE is mainly involved in the production of $\mathrm{H}_{2} \mathrm{~S}$ in kidneys and CVS while CBS controls $\mathrm{H}_{2} \mathrm{~S}$ production in CNS [20]. Approximately, $90 \%$ of $\mathrm{H}_{2} \mathrm{~S}$ production in the brain is carried out by 3-MST [21]. $\mathrm{H}_{2} \mathrm{~S}$ is a vasorelaxant [19,22-24], anti-hypertensive [25-27], antioxidant $[13,14,28,29]$ and anti-inflammatory agent [15,30]. Data also indicate that $\mathrm{H}_{2} \mathrm{~S}$ may produce its therapeutic role as anti-inflammatory and antioxidant pathway in the kidney, which is dependent on the carbon monoxide pathway (CO) [31].

Acute administration of NaHS, either topically on to the kidneys [32,33] or through intravenous flushing in to the kidneys [34,35], has been studied in a renal IRI model in normotensive rats. However, to the best of our knowledge, the effects of chronic treatment with NaHS in a renal IRI model, both for normal and diseased models, are as-yet unknown. Thus, in the present study we investigated the effects of pre-treatment with NaHS for 35 days on renal function in both normotensive as well as L-NAME-induced hypertensive rats following IRI. The present study included an L-NAME-induced hypertensive model, as this model is characterized by increased oxidative stress [36,37] as well as decreased endogenous concentration of $\mathrm{H}_{2} \mathrm{~S}$ [27]. Therefore, the kidneys of hypertensive rats would be more capable of rendering the extent of IRI compared to normotensive rats. We hypothesized that chronic administration of NaHS would improve the physiological concentration of $\mathrm{H}_{2} \mathrm{~S}$, which would induce its antioxidant potential by increasing antioxidant markers like T-SOD and GSH and decreasing pro-oxidant markers like MDA in the plasma of normotensive and hypertensive rats. This elevated antioxidant mechanism and inhibition of NF-kB activation would downregulate ICAM-1 expression through its anti-inflammatory potential. We hypothesized that enhancement of antioxidant and anti-inflammatory mechanisms by $\mathrm{H}_{2} \mathrm{~S}$ would reduce the degree of IRI in normotensive and hypertensive rats.

\section{Materials and Methods}

\subsection{Animals}

Sixty-four male Wistar Kyoto rats (WKY) weighing $220 \pm 20$ g were received from the Animal Research and Service Centre (ARASC) at Universiti Sains Malaysia (USM) and brought to the transit room of the School of Pharmaceutical Sciences, USM, where they were acclimatized for 5 days. All the animals were housed in standard cages with free access to chow food (protein $22 \%$; fat $3 \%$; fibre: $3 \%$; ash: $8 \%$; calcium: $1 \%$; phosphorus: $0.8-1.2 \%$; sodium: $0.18-0.24 \%$; potassium: $1.0-1.1 \%$; and moisture: $13 \%$ ) and 
water. All the experimental procedures were approved by the Universiti Sains Malaysia Animal Ethics committee with approval letter reference no. USM/Animal Ethics Approval/2015/(95) (649).

\subsection{Induction of Hypertension}

L-NAME was dissolved in drinking water at a dose of $40 \mathrm{mg} / \mathrm{kg} /$ day to induce hypertension $[38,39]$. The stock solution of L-NAME was prepared on a daily basis. LNAME was administered for 28 days, started on day 8 until the end of the study protocol. The dose of L-NAME was adjusted according to body weight of the rats three times per week.

\subsection{Exogenous Administration of $\mathrm{NaHS}$}

$\mathrm{NaHS}$ was administered i.p. at a dose of $56 \mu \mathrm{mol} / \mathrm{kg}$ daily for a period of 35 days [40,41]. Stock solution of NaHS was prepared daily by dissolving NaHS in normal saline $(0.9 \% w / v)$. The dose of NaHS was adjusted according to body weight of the rats three times per week.

\subsection{Administration of $P A G$}

PAG was administered i.p. at a single dose of $50 \mathrm{mg} / \mathrm{kg}$ on day 36 (acute experiment day) [32]. PAG solution was prepared daily by dissolving PAG in normal saline $(0.9 \% w / v)$.

\subsection{Drugs and Chemicals}

NaHS was purchased from the USA (Sigma-Aldrich) and L-NAME (Sigma-Aldrich, Schaffhausen, China), PAG (Sigma-Aldrich, Schaffhausen, Switzerland) and pentobarbital sodium (Dorminal 20\%) from Holland (Alfasan, Woerden, The Netherlands).

\subsection{Experimental Protocol}

Animals were divided into two groups, namely WKY and L-NAME-induced hypertension. Each group was subdivided into four groups ( $n=8$, each group) consisting of (i) rats that received saline (WKY-SHAM and L-NAME-SHAM), (ii) rats that received saline (WKY-CONTROL and L-NAME-CONTROL), (iii) rats that received $\mathrm{H}_{2} \mathrm{~S}$ treatment (WKY+NaHS and L-NAME+NaHS) and (iv) rats that received PAG treatment (WKY+PAG and L-NAME+PAG). All groups of rat underwent the same surgical procedure to induce IRI. The sham-operated group underwent the same surgical procedure, except that the IRI was not induced.

\subsection{Collection of Metabolic Data}

The animals were kept individually in metabolic cages $\left(\right.$ Nalgene ${ }^{\circledR}$, Thermo Scientific, Beaumont, PA, USA) and body weight, $24 \mathrm{~h}$ urine output and water intake were measured (data not shown) on days 0,21 and 35. In order to remove impurities, the urine samples were centrifuged at 10,000 $\times g$ rpm (Hettich EBA 8S, Zentrifugen, Hettich Instruments, Illinois, Chicago, USA) for $3 \mathrm{~min}$. Blood samples were also collected (300-500 $\mu \mathrm{L})$ on days 0,21 and 35 from the lateral tail vein and centrifuged at $10,000 \times \mathrm{g} \mathrm{rpm}$ for $10 \mathrm{~min}$ to separate clear plasma [42]. Both urine and plasma samples were stored at $-30{ }^{\circ} \mathrm{C}$ for further biochemical estimation of creatinine, potassium and sodium on days 0,21 and 35 . Finally, on day 36 the acute experiments were performed to induce IRI.

\subsection{Non-Invasive Blood Pressure (NIBP) Measurment}

Non-invasive blood pressure (NIBP) was measured using the tail-cuff method (CODA ${ }^{\mathrm{TM}}$, Kent Scientific Corporation, Torrington, CT, USA) in conscious animals on days 0, 21 and 35. Thereafter, invasive blood pressure was measured directly in anaesthetized animals on day 36 during the acute experimental procedure. 


\subsection{Acute Experiment}

The experimental procedure for the acute surgical experiment was based on previously reported studies [42,43]. The rats were fasted overnight for $8-10 \mathrm{~h}$ and then anesthetized using pentobarbital sodium $(60 \mathrm{mg} / \mathrm{kg}$, i.p.). A tracheotomy was performed by inserting a tracheal tube PP 240 (Portex Ltd. Kent, London, UK) into the trachea to ensure clear airway passage. Thereafter, the left jugular vein was cannulated in order to administer a maintenance dose of anaesthesia at a dose of $12.5 \mathrm{mg} / \mathrm{kg}$ as required. The right carotid artery was also cannulated, and the cannula was connected to the pressure transducer system (P23 ID Gould, Statham Instruments, London, UK), which was linked to the data acquisition system (PowerLab ${ }^{\circledR}$, ADInstruments, Sydney, Australia) via a Quad amp (ADInstruments, New South Wales, Australia) for continuous measurement of the mean arterial pressure (MAP), systolic blood pressure (SBP) and heart rate (HR) using Chart Pro (V.5.5) software on a Hewlett Packard Centrino Core2 Duo computer operating Windows XP. Afterwards, an abdominal midline incision was made to expose the left kidney and left iliac artery. The iliac artery was cannulated to measure iliac blood pressure (data not shown). The iliac cannula was also connected to a pressure transducer (P23 ID Gould, Statham Instruments, Nottingham, UK) coupled to a computerized data acquisition system (PowerLab, AD Instruments, Sydney, NSW, Australia). The iliac cannula was further connected to an infusion pump for the continuous infusion of normal saline $(0.9 \% \mathrm{NaCl})$ at a rate of $3 \mathrm{~mL} / \mathrm{h}$. Finally, RCBP was measured using a laser Doppler flow probe (OxyFlow, ADInstruments, New South Wales, Australia), which was positioned on the dorsal surface of the posterior end of the exposed left kidney. The probe was connected to a laser Doppler flow meter (ADInstruments), which was directly linked to the data acquisition system (PowerLab, ADInstruments). The urinary bladder was catheterized to collect urine samples during the surgical procedure. On completion of surgery, the rat was given a period of $1 \mathrm{~h}$ for stabilization.

\subsection{Collection of Blood and Urine Samples}

After stabilization, baseline values of SBP, MAP, HR and RCBP were recorded. Blood $(1.5 \mathrm{~mL})$ was collected from the carotid artery cannula, centrifuged to obtain plasma and finally stored at $-80^{\circ} \mathrm{C}$ for future biochemical tests. In order to restore the withdrawn blood, the centrifuged blood without plasma was resuspended with $0.9 \%$ normal saline and infused slowly through a jugular vein cannula. A recovery period of $30 \mathrm{~min}$ was provided for stabilization in order for variables to return to baseline levels. Once the rat was stabilized, the left renal artery was clamped for $30 \mathrm{~min}$ with a non-traumatic arterial clamp (Tenko, Germany) in order to induce renal ischemia according to a previous reported procedure [44]. A $30 \mathrm{~min}$ ischemia was followed by a reperfusion phase of $3 \mathrm{~h}$. At the end of the reperfusion phase, approximately $3-5 \mathrm{~mL}$ of blood was withdrawn from the carotid artery and centrifuged to separate plasma. Urine samples $(2-3 \mathrm{~mL})$ were also collected before and after renal ischemia. Both plasma and urine samples were stored at $-80{ }^{\circ} \mathrm{C}$ for future biochemical tests. The animal was then euthanized with an overdose of pentobarbital sodium $(200 \mathrm{mg} / \mathrm{kg})$. The left kidney was then removed and weighed in order to calculate the kidney index according to an already reported method [42].

$$
\text { Kidney Index }=\frac{\text { Kidney weight }}{\text { Body weight }} \times 100
$$

\subsection{Measurement of Renal Functional Parameters}

Concentration of creatinine was measured in both plasma and urine using the colorimetric method according to an already published procedure [45]. Readings were taken at $520 \mathrm{~nm}$ using a 96-well microplate reader $\left(\mathrm{Epoch}^{\mathrm{TM}}\right.$ Microplate Spectrophotometer, BioTek Instruments, Einooski, Vermont, USA). Creatinine clearance was then calculated from the readings of urinary and plasma creatinine. Sodium and potassium in plasma and urine were measured using a flame photometer (Jenway Limited, Felsted, UK). These read- 
ings were then used to calculate the fractional excretion of sodium $\left(\mathrm{FE}_{\mathrm{Na}}\right)$ and fractional excretion of potassium $\left(\mathrm{FE}_{\mathrm{K}}\right)$.

\subsection{Measurement of $\mathrm{H}_{2} \mathrm{~S}$ Concentration}

$\mathrm{H}_{2} \mathrm{~S}$ concentration in plasma was measured spectrophotometrically $[40,46]$ on days 0,21 and 36 . The procedure involved the addition of $300 \mu \mathrm{L}$ zinc acetate $(1 \% w / v)$ into centrifuge tubes, and then $100 \times g \mu \mathrm{L}$ of plasma samples and $50 \mu \mathrm{L}$ of distilled water were added into the tubes. The purpose of the zinc acetate in the procedure was to trap $\mathrm{H}_{2} \mathrm{~S}$. Then, $200 \mu \mathrm{L}$ of N,N-dimethyl-P-phenylenediamine sulphate $(20 \mathrm{mM}$ in $7.2 \mathrm{M} \mathrm{HCl})$ was added after $5 \mathrm{~min}$ in order to stop the reaction. This step was immediately followed by the addition of $200 \mu \mathrm{L}$ ferric chloride $(30 \mathrm{mM}$ in $1.2 \mathrm{M} \mathrm{HCl})$. All the samples were then kept in the dark for $20 \mathrm{~min}$. Then, $150 \mu \mathrm{L}$ of trichloro acetic acid $(10 \% \mathrm{w} / v)$ was added to all samples in order to precipitate out the proteins. Finally, samples were then centrifuged and readings of supernatant were taken at $670 \times g \mathrm{~nm}$. The concentration of $\mathrm{H}_{2} \mathrm{~S}$ in the plasma was calculated by using the standard curve for $\mathrm{H}_{2} \mathrm{~S}$.

\subsection{Measurement of Oxidative Stress Markers}

Oxidative stress markers in plasma, such as malondialdehyde (MDA), total superoxide dismutase (T-SOD) and glutathione (GSH), were measured on day 36 (acute experiment day) at the pre-ischemia and reperfusion phases using MDA, T-SOD and GSH commercial kits (Institute of Biological Engineering of Nanjing Jianchen, Nanjing, China). All the procedures for these kits were followed according to the instructions given in their respective manuals.

\subsection{ICAM-1 and NF-kB Measurement in the Plasma and Kidney Tissues of WKY and L-NAME-Treated Groups}

ICAM-1 and NF-kB concentrations were measured in plasma and kidney tissues of all animals of the WKY and L-NAME groups at the pre-ischemia and reperfusion phases on day 36. Kidney levels of ICAM-1 and NF-kB in the pre-ischemia phase were measured in different sets of animals and the experiment was terminated after taking kidney samples. For quantitative measurement of ICAM-1 levels, a Quantikine ELISA Rats ICAM-1/CD54 ELISA kit (R\&D Systems, Inc., USA) was used. The principle of this assay kit follows that of the quantitative sandwich enzyme immunoassay technique. Similarly, for quantitative measurement of rat NF-kB concentration in the plasma and kidney tissue, a Rat Nuclear Factor-Kappa B (NF-kB) ELISA kit (CUSABIO Biotech Co., Ltd.) was used. This assay kit also followed the quantitative sandwich enzyme immunoassay technique. All the procedures for both the Rat sICAM-1/CD 54 immunoassay and Rat Nuclear Factor-Kappa $\mathrm{B}(\mathrm{NF}-\mathrm{kB})$ immunoassay were followed according to the instructions given in the manuals. The optical density of each sample for both ICAM-1 and NF-kB was measured spectrophotometrically at $450 \mathrm{~nm}$. Then, the concentrations of ICAM- 1 and NF-kB in the plasma and kidney tissue samples were calculated against their respective standard curves.

\subsection{Histopathology of Rat Kidney Tissues of WKY and L-NAME Groups}

Histopathology of kidney tissue followed a previously reported procedure [41]. Briefly, kidneys of all groups of WKY and L-NAME rats undergoing ischemia-reperfusion injury were extracted at the end of the experiments and placed in the $10 \%$ formalin. Kidneys were subjected to subsequent events of embedding, trimming, sectioning and staining with haematoxylin and eosin.

\subsection{Statistical Analysis}

All the data (mean \pm SEM) were analysed statistically using the GraphPad statistical software package (GraphPad Prism Statistics for Windows; version 5.0, San Diego, CA, USA). Data were analysed and compared using repeated measures one-way ANOVA 
followed by Bonferroni's post hoc test. For all comparisons, differences between the means were considered significant when $p<0.05$.

\section{Results}

\subsection{Systemic Hemodynamic Parameters}

SBP, MAP and HR were measured on days 0,21 and 35 with a non-invasive method in both WKY and L-NAME-induced hypertensive rats (Table 1). In the WKY-CONTROL groups no significant changes in SBP, MAP or HR were observed on days 21 and 35 compared to their respective groups on day 0 . On the other hand, SBP and MAP were significantly increased (all $p<0.05$ ) in L-NAME-induced hypertensive groups on days 21 and 35 when compared to their respective groups on days 0. Similarly, HR in L-NAMEinduced hypertensive groups was significantly increased (all $p<0.05)$ on day 35 compared to both days 0 and 21. In the L-NAME+NaHS group, HR was significantly increased $(p>0.05)$ on day 35 compared to days 0 and 21 . Moreover, SBP and MAP were significantly increased (all $p<0.05$ ) in L-NAME-induced hypertensive rats on days 21 and 35 compared to the WKY-CONTROL group on days 21 and 35. 
Table 1. Hemodynamics and renal functional parameters in all experimental groups of WKY and L-NAME rats during metabolic collection on days 0,21 and 35.

\begin{tabular}{|c|c|c|c|c|}
\hline Parameters & Groups & Day 0 & Day 21 & Day 35 \\
\hline \multirow[t]{8}{*}{ SBP } & WKY-SHAM & $117 \pm 3$ & $118 \pm 3$ & $119 \pm 3$ \\
\hline & WKY-CONTROL & $117 \pm 5$ & $120 \pm 3$ & $119 \pm 2$ \\
\hline & $\mathrm{WKY}+\mathrm{NaHS}$ & $121 \pm 3$ & $117 \pm 3$ & $113 \pm 2$ \\
\hline & WKY+PAG & $119 \pm 4$ & $116 \pm 3$ & $117 \pm 3$ \\
\hline & L-NAME-SHAM & $118 \pm 4$ & $162 \pm 4^{\Psi}$ & $199 \pm 9^{\Psi, \phi}$ \\
\hline & L-NAME-CONTROL & $119 \pm 3$ & $180 \pm 4^{\Psi}$ & $194 \pm 9^{\Psi, \phi, \delta}$ \\
\hline & L-NAME+NaHS & $118 \pm 2$ & $139 \pm 3^{\Psi}$ & $154 \pm 3^{\Psi, ф, Л ~}$ \\
\hline & L-NAME+PAG & $116 \pm 3$ & $173 \pm 6^{\Psi}$ & $197 \pm 10^{\Psi, \phi}$ \\
\hline \multirow[t]{8}{*}{ MAP } & WKY-SHAM & $98 \pm 2$ & $99 \pm 2$ & $100 \pm 3$ \\
\hline & WKY-CONTROL & $99 \pm 4$ & $98 \pm 1$ & $99 \pm 1$ \\
\hline & $\mathrm{WKY}+\mathrm{NaHS}$ & $100 \pm 2$ & $99 \pm 2$ & $95 \pm 1$ \\
\hline & WKY+PAG & $100 \pm 2$ & $98 \pm 1$ & $98 \pm 2$ \\
\hline & L-NAME-SHAM & $99 \pm 2$ & $142 \pm 3^{\Psi}$ & $176 \pm 6^{\Psi, \phi}$ \\
\hline & L-NAME-CONTROL & $99 \pm 2$ & $144 \pm 3^{\Psi}$ & $177 \pm 10^{\Psi, \phi, \delta}$ \\
\hline & L-NAME+NaHS & $99 \pm 1$ & $120 \pm 2^{\Psi}$ & $141 \pm 8^{\Psi, Ф, Л ~}$ \\
\hline & L-NAME+PAG & $98 \pm 1$ & $142 \pm 4^{\Psi}$ & $175 \pm 6^{\Psi, \phi}$ \\
\hline \multirow[t]{8}{*}{ HR } & WKY-SHAM & $326 \pm 12$ & $311 \pm 9$ & $319 \pm 8$ \\
\hline & WKY-CONTROL & $326 \pm 15$ & $331 \pm 12$ & $324 \pm 11$ \\
\hline & $\mathrm{WKY}+\mathrm{NaHS}$ & $313 \pm 14$ & $304 \pm 9$ & $321 \pm 7$ \\
\hline & $\mathrm{WKY}+\mathrm{PAG}$ & $308 \pm 19$ & $304 \pm 20$ & $318 \pm 12$ \\
\hline & L-NAME-SHAM & $303 \pm 21$ & $338 \pm 32$ & $384 \pm 15^{\Psi, \phi}$ \\
\hline & L-NAME-CONTROL & $308 \pm 12$ & $340 \pm 16$ & $387 \pm 18^{\Psi, \phi, \delta}$ \\
\hline & L-NAME+NaHS & $310 \pm 7$ & $338 \pm 7$ & $355 \pm 13^{\Psi}$ \\
\hline & L-NAME+PAG & $300 \pm 12$ & $327 \pm 10$ & $394 \pm 15^{\Psi, \phi}$ \\
\hline \multirow{5}{*}{$\mathrm{FE}_{\mathrm{Na}}$} & WKY-SHAM & $0.72 \pm 0.09$ & $0.69 \pm 0.1$ & $0.74 \pm 0.07$ \\
\hline & WKY-CONTROL & $0.67 \pm 0.04$ & $0.66 \pm 0.1$ & $0.69 \pm 0.16$ \\
\hline & $\mathrm{WKY}+\mathrm{NaHS}$ & $0.67 \pm 0.02$ & $0.68 \pm 0.02$ & $0.69 \pm 0.01$ \\
\hline & WKY+PAG & $0.65 \pm 0.02$ & $0.68 \pm 0.02$ & $0.68 \pm 0.03$ \\
\hline & L-NAME-SHAM & $0.72 \pm 0.02$ & $0.96 \pm 0.03^{\Psi}$ & $1.51 \pm 0.06^{\Psi, \phi}$ \\
\hline
\end{tabular}


Table 1. Cont.

\begin{tabular}{ccccc}
\hline Parameters & Groups & Day 0 & Day 21 & Day 35 \\
\hline & L-NAME-CONTROL & $0.68 \pm 0.03$ & $0.98 \pm 0.03^{\Psi}$ & $1.56 \pm 0.05^{\Psi, \phi, \delta}$ \\
\hline L-NAME+NaHS & $0.72 \pm 0.02$ & $0.84 \pm 0.02$ & $0.94 \pm 0.02^{\Psi, л}$ \\
\hline L-NAME+PAG & $0.69 \pm 0.03$ & $0.96 \pm 0.03^{\Psi}$ & $1.61 \pm 0.08^{\Psi, \phi}$ \\
\hline WE & WKY-SHAM & $14 \pm 3.2$ & $13 \pm 2.9$ & $13 \pm 2.0$ \\
\hline WKY-CONTROL & $13 \pm 1.1$ & $13 \pm 5.0$ & $13 \pm 3.0$ \\
\hline WKY+NaHS & $13 \pm 2.8$ & $12.09 \pm 1.3$ & $12 \pm 1.6$ \\
\hline WKY+PAG & $12 \pm 1.8$ & $12 \pm 1.3$ & $11 \pm 1.1$ \\
\hline L-NAME-SHAM & $13 \pm 1.9$ & $18 \pm 3.0^{\Psi}$ & $27 \pm 3.9^{\Psi, \phi}$ \\
\hline L-NAME-CONTROL & $12 \pm 1.8$ & $18 \pm 2.9^{\Psi}$ & $27 \pm 4.1^{\Psi, \phi, \delta}$ \\
\hline L-NAME+NaHS & $13 \pm 1.9$ & $15 \pm 2.2$ & $19 \pm 2.3^{\Psi, \text { ग }}$ \\
\hline L-NAME+PAG & $12 \pm 1.9$ & $16 \pm 1.4^{\Psi}$ & $25 \pm 3.6^{\Psi, \phi}$ \\
\hline WKY-SHAM & $5.36 \pm 0.62$ & $5.21 \pm 1.02$ & $4.63 \pm 0.54$ \\
\hline WKY-CONTROL & $7.82 \pm 1.42$ & $7.12 \pm 1.59$ & $5.64 \pm 0.58$ \\
\hline WKY+NaHS & $8.06 \pm 0.41$ & $6.51 \pm 2.42$ & $6.71 \pm 1.52$ \\
\hline L-NAME-CONTROL & $7.87 \pm 3.0$ & $4.49 \pm 2.1^{\Psi}$ & $3.09 \pm 1.3^{\Psi, \delta}$ \\
\hline L-NAME+NaHS & $4.83 \pm 0.5$ & $3.41 \pm 0.2$ & $2.93 \pm 0.3$ \\
\hline L-NAME+PAG & $5.63 \pm 0.9$ & $3.45 \pm 1.0^{\Psi}$ & $2.56 \pm 0.6^{\Psi}$ \\
\hline
\end{tabular}

Data were analysed using repeated measures ANOVA followed by Bonferroni's post hoc test. Data are presented as means $\pm \operatorname{SEM}\left(n=6\right.$, per group). ${ }^{\Psi} p<0.05$ vs. day 0 of respective groups; $\phi p<0.05$ vs. day 21 of respective groups; ${ }^{\delta} p<0.05$ vs. WKY-CONTROL on day $35 ;{ }^{\pi} p<0.05$ vs. L-NAME-CONTROL on day 35. SBP $=$ systolic blood pressure, $\mathrm{MAP}=$ mean arterial pressure, $\mathrm{HR}=$ heart rate. WKY = Wistar Kyoto rats, L-NAME = L-nitromethyl-arginine-ester, $\mathrm{PAG}=\mathrm{dL}$-propargylglycine.

\subsection{Renal Functional Parameters}

$\mathrm{FE}_{\mathrm{Na}}, \mathrm{FE}_{\mathrm{K}}$ and creatinine clearance $(\mathrm{Cr} . \mathrm{Cl})$ were measured in both WKY and L-NAMEinduced hypertensive groups on days 0,21 and 35 (Table 1). In WKY groups no significant change (all $p>0.05$ ) in $\mathrm{FE}_{\mathrm{Na}}, \mathrm{FE}_{\mathrm{K}}$ and $\mathrm{Cr}$. $\mathrm{Cl}$ was observed on day 21 when compared to their respective groups on day 0 , nor on day 35 when compared to their respective groups on both days 0 and 21. On the other hand, $\mathrm{FE}_{\mathrm{Na}}$ and $\mathrm{FE}_{\mathrm{K}}$ were significantly increased (all $p<0.05)$ in L-NAME-induced hypertensive groups on day 21 compared to their respective groups on day 0 and on day 35 when compared to their respective groups on both days 0 and 21, except the L-NAME+NaHS group, in which both $\mathrm{FE}_{\mathrm{Na}}$ and $\mathrm{FE}_{\mathrm{K}}$ were significantly increased $(p<0.05)$ on day 35 compared to day 0 but not significantly increased when compared to day 21. Pre-treatment with NaHS significantly reduced $(p<0.05)$ both $\mathrm{FE}_{\mathrm{Na}}$ and $\mathrm{FE}_{\mathrm{K}}$ in the L-NAME+NaHS group when compared to its L-NAME control group on day 35. $\mathrm{Cr} . \mathrm{Cl}$ in the L-NAME-induced hypertensive groups was significantly reduced (all $p<0.05$ ) on day 21 as well as on day 35 when compared to their respective groups on day 0 , except in the L-NAME+NaHS group in which no significant changes $(p>0.05)$ in $\mathrm{Cr}$. Cl were observed on days 21 or 35 compared to day 0 . Moreover, $\mathrm{FE}_{\mathrm{Na}}$ and $\mathrm{FE}_{\mathrm{K}}$ were significantly increased $(p<0.05)$, while $\mathrm{Cr}$. Cl was significantly reduced $(p<0.05)$, in L-NAME-induced hypertensive rats on day 35 compared to WKY rats on the same day.

\section{3. $\mathrm{H}_{2} \mathrm{~S}$ Concentration in Plasma}

The plasma concentration of $\mathrm{H}_{2} \mathrm{~S}$ in both WKY and L-NAME-induced hypertensive groups was measured on days 0, 21 and day 36 (Figure 1). In WKY groups, no significant change (all $p>0.05$ ) in plasma $\mathrm{H}_{2} \mathrm{~S}$ concentration was observed on day 21 when compared 
to their respective groups on day 0 or on day 36 when compared to their respective groups on both days 0 and 21, except the WKY+NaHS group, which was pre-treated with NaHS and showed a significant increase $(p<0.05)$ in plasma concentration of $\mathrm{H}_{2} \mathrm{~S}$ on day 36 compared to its respective group on day 0 and also to the WKY-CONTROL group on the same day. On the other hand, administration of PAG in the WKY+PAG group showed a significant decrease $(p<0.05)$ in plasma concentration of $\mathrm{H}_{2} \mathrm{~S}$ on day 36 when compared to its respective group on day 0 and also to the WKY-CONTROL and WKY+NaHS groups on the same day. In the L-NAME-induced hypertensive groups, concentration of $\mathrm{H}_{2} \mathrm{~S}$ in the plasma was reduced significantly (all $p<0.05$ ) on day 21 when compared to their respective groups on day 0 and on day 36 when compared to their respective groups on both days 0 and 21, except the L-NAME+NaHS group in which there was no significant change $(p>0.05)$ in plasma $\mathrm{H}_{2} \mathrm{~S}$ concentration on day 36 compared to days 0 and 21 , but the $\mathrm{H}_{2} \mathrm{~S}$ concentration in the L-NAME+NaHS group was found to be significantly increased $(p<0.05)$ on day 36 when compared to the L-NAME-CONTROL and L-NAME+PAG groups on the same day. The concentration of $\mathrm{H}_{2} \mathrm{~S}$ in plasma was significantly lower $(p<0.05)$ in the L-NAME-induced hypertensive rats on day 36 compared to WKY rats on the same day.

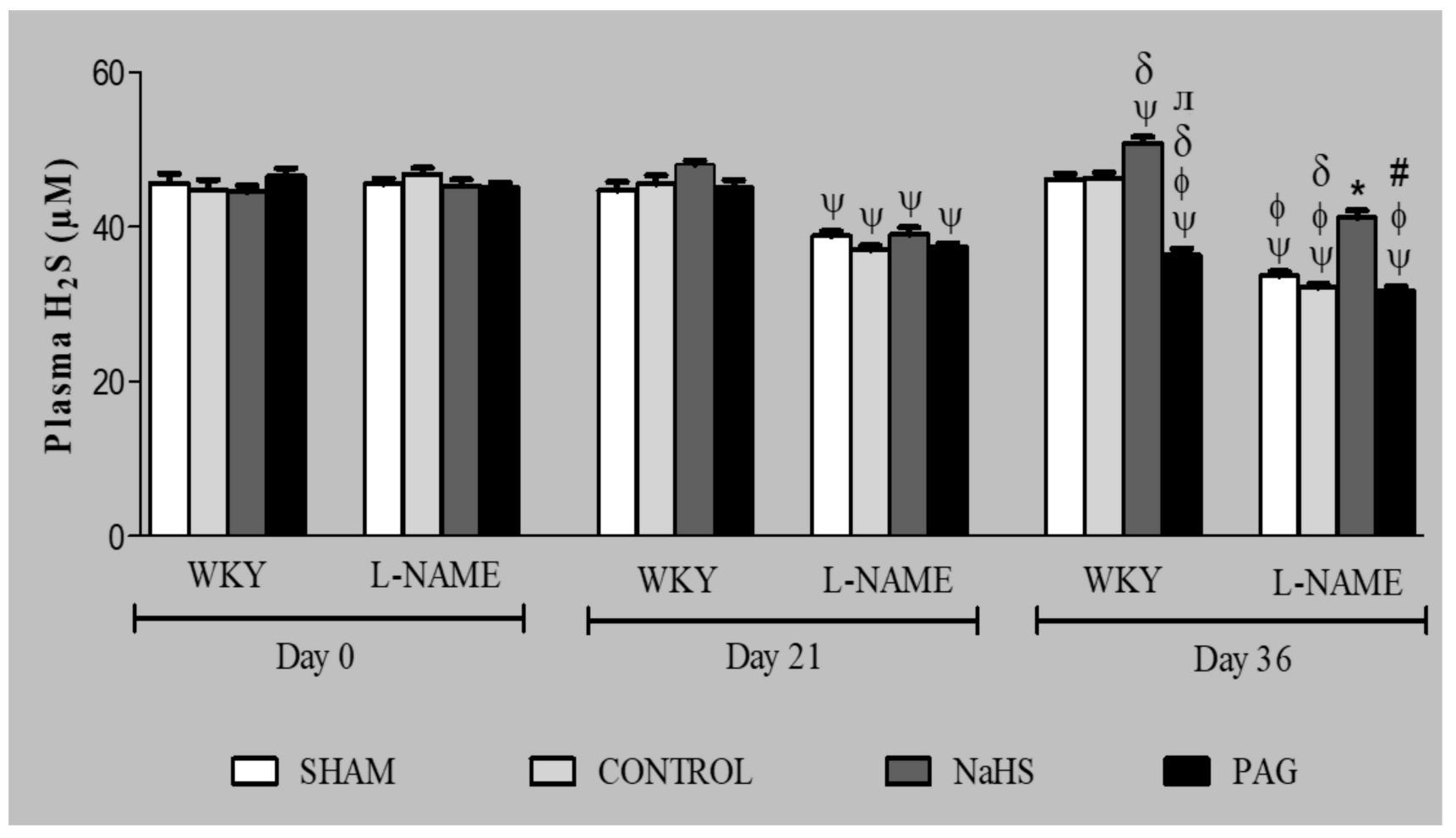

Figure 1. Plasma $\mathrm{H}_{2} \mathrm{~S}$ concentrations on days 0,21 and $36(n=6)$ in different experimental groups of WKY and L-NAME rats. Data were analysed using repeated measures ANOVA followed by Bonferroni's post hoc test. ${ }^{\Psi} p<0.05$ vs. day 0 of respective groups; ${ }^{\phi} p<0.05$ vs. day 21 of respective groups; ${ }^{\delta} p<0.05$ vs. WKY-CONTROL on day $36 ;{ }^{\pi} p<0.05$ vs. WKY+NaHS on day $36 ;{ }^{*} p<0.05$ vs. L-NAME-CONTROL on day 36; ${ }^{\#} p<0.05$ vs. L-NAME+NaHS on day 36. $\mathrm{H}_{2} \mathrm{~S}=$ hydrogen sulphide, WKY = Wistar Kyoto rats, L-NAME = L-nitro-methyl-arginine-ester, PAG = dL-propargylglycine. 


\subsection{Systemic Hemodynamics on Acute Experiment Day}

The SBP, MAP and HR were also measured on acute experiment day using an invasive method (Table 2). All groups of WKY rats showed no significant differences (all $p<0.05)$ in SBP, MAP and HR. However, the same haemodynamic parameters were increased significantly (all $p<0.05$ ) in L-NAME-induced hypertensive rats compared to WKY rats. The L-NAME group, when pre-treated with NaHS (L-NAME+NaHS), showed significantly reduced SBP, MAP and HR (all $p<0.05$ ) compared to the L-NAME-CONTROL and L-NAME+PAG groups.

Table 2. Hemodynamics, kidney weight and kidney index for all experimental groups of WKY and L-NAME rats on acute experiment day (day 36).

\begin{tabular}{|c|c|c|c|c|c|c|}
\hline Groups & SBP (mmHg) & MAP (mmHg) & HR (rpm) & BW (g) & KW (g) & KI (\%) \\
\hline WKY-SHAM & $113 \pm 5$ & $100 \pm 4$ & $316 \pm 9$ & $305 \pm 10$ & $0.90 \pm 0.01$ & $0.297 \pm 0.01$ \\
\hline WKY-CONTROL & $111 \pm 6$ & $99 \pm 2$ & $311 \pm 14$ & $315 \pm 10$ & $1.06 \pm 0.04^{\Psi}$ & $0.336 \pm 0.02^{\Psi}$ \\
\hline WKY+NaHS & $110 \pm 4$ & $98 \pm 3$ & $300 \pm 8$ & $298 \pm 7^{\#}$ & $0.94 \pm 0.01$ \# & $0.317 \pm 0.00$ \\
\hline WKY+PAG & $113 \pm 3$ & $99 \pm 1$ & $318 \pm 20$ & $302 \pm 5$ & $1.03 \pm 0.05^{\Psi, \delta}$ & $0.340 \pm 0.02^{\Psi}$ \\
\hline L-NAME-SHAM & $198 \pm 9$ & $175 \pm 6$ & $374 \pm 16$ & $294 \pm 6$ & $0.98 \pm 0.02$ & $0.332 \pm 0.01$ \\
\hline $\begin{array}{l}\text { L-NAME- } \\
\text { CONTROL }\end{array}$ & $193 \pm 9^{\#}$ & $176 \pm 10^{\#}$ & $379 \pm 23^{\#}$ & $285 \pm 7^{\#}$ & $1.09 \pm 0.05^{\phi}$ & $0.384 \pm 0.02 \phi$ \\
\hline L-NAME+NaHS & $153 \pm 3^{\phi,:}$ & $140 \pm 8^{\phi, ¥}$ & $352 \pm 18$ & $297 \pm 4$ & $1.04 \pm 0.06$ & $0.349 \pm 0.01$ \\
\hline L-NAME+PAG & $196 \pm 10^{\text {л }}$ & $174 \pm 6^{\pi}$ & $389 \pm 14^{\text {л }}$ & $285 \pm 7$ & $1.174 \pm 0.02 \phi, ¥, \pi$ & $0.412 \pm 0.01$ ф,л \\
\hline
\end{tabular}

Data were analysed using one-way ANOVA followed by Bonferroni's post hoc test. Data presented as means \pm SEM ( $n=6$, per group). ${ }^{\Psi} p<0.05$ vs. WKY-SHAM; ${ }^{\phi} p<0.05$ vs. L-NAME-SHAM; ${ }^{\#} p<0.05$ vs. WKY-CONTROL; ${ }^{\delta} p<0.05$ vs. WKY+NaHS; ${ }^{*} p<0.05$ vs. L-NAME-CONTROL; ${ }^{\pi} p<0.05$ vs. L-NAME+NaHS. SBP = systolic blood pressure, MAP = mean arterial pressure, HR = heart rate, $\mathrm{BW}=$ body weight, $\mathrm{KW}$ = kidney weight, $\mathrm{KI}$ = kidney index, WKY = Wistar Kyoto rats, L-NAME = L-nitro-methyl-arginine-ester, PAG $=$ dL-propargylglycine.

\subsection{Body Weight, Kidney Weight and Kidney Index}

The body weight (BW), kidney weight (KW) and kidney index (KI) were also measured on acute experiment day (Table 2). Both the KW and KI were significantly higher (both $p<0.05)$ in the CONTROL and PAG-administered groups in both WKY and L-NAMEinduced hypertensive groups. It was observed that pre-treatment with NaHS did not exert any significant effect on KW and KI except in the WKY+NaHS group, in which KW was significantly reduced $(p<0.05)$ when compared to the WKY-CONTROL and WKY+PAG groups. KW was significantly high $(p<0.05)$ in the L-NAME+PAG group when compared to the L-NAME-CONTROL and L-NAME+NaHS groups. Similarly, KI was also significantly high $(p<0.05)$ in the L-NAME+PAG group when compared to the L-NAME+NaHS group. It was also observed that BW and KI were significantly high $(p<0.05)$ in L-NAME-induced hypertensive rats when compared to WKY rats.

\subsection{RCBP in the Pre-Ischemia and Reperfusion Phases}

Renal cortical blood perfusion (RCBP) was measured at the pre-ischemia and reperfusion phases (Figure 2). A significant decline (all $p<0.05)$ in RCBP was observed at the reperfusion phase in both the WKY and L-NAME-induced hypertensive groups when compared to their respective groups at the pre-ischemia phase, except in the SHAM groups of both WKY and L-NAME-induced hypertensive rats, in which no ischemia was induced. No significant effect ( $p>0.05$ ) of NaHS was observed on RCBP in the WKY+NaHS group when compared to the WKY-CONTROL and WKY+PAG groups. However, on the other hand, a significant increase $(p<0.05)$ in RCBP was found in the L-NAME+NaHS group when compared to the WKY-CONTROL and WKY+PAG groups. It was noticed that RCBP was significantly lower $(p<0.05)$ in L-NAME-induced hypertensive rats compared to WKY rats. 


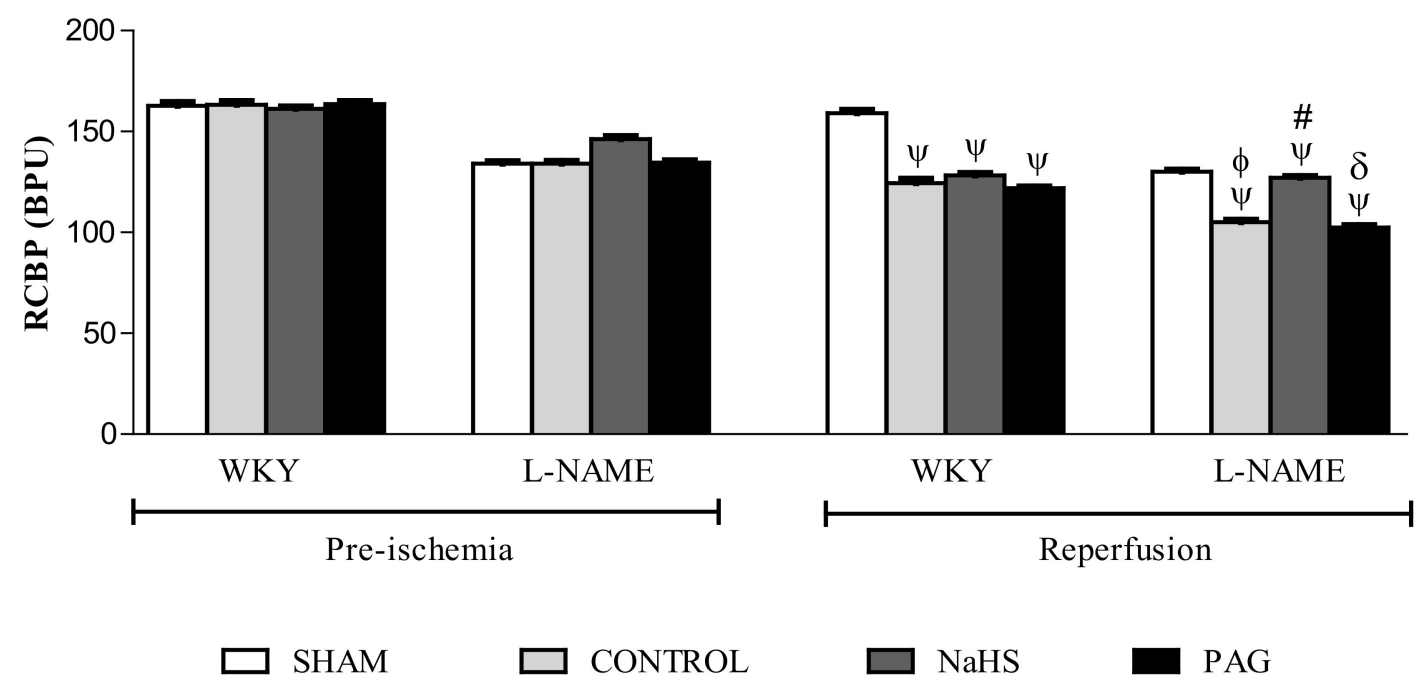

Figure 2. RCBP measurements in different experimental groups of WKY and L-NAME rats before and after ischemia $(n=6)$. Data were analysed using one-way ANOVA followed by Bonferroni's post hoc test. ${ }^{\Psi} p<0.05$ vs. pre-ischemic phase of respective groups; ${ }^{\phi} p<0.05$ vs. WKY-CONTROL at reperfusion phase; ${ }^{\#} p<0.05$ vs. L-NAME-CONTROL at reperfusion phase; ${ }^{\delta} p<0.05$ vs. L-NAME+NaHS at reperfusion phase. RCBP $=$ renal cortical blood perfusion, WKY $=$ Wistar Kyoto rats, $\mathrm{PAG}=\mathrm{dL}$-propargylglycine, $\mathrm{L}-\mathrm{NAME}=\mathrm{L}$-nitro-methyl-arginine-ester.

\subsection{Renal Functional Parameters at the Pre-Ischemia and Reperfusion Phases}

Renal functional parameters like $\mathrm{FE}_{\mathrm{Na}}, \mathrm{FE}_{\mathrm{K}}$ and plasma creatinine were also measured at the pre-ischemia and reperfusion phases (Figure 3). A significant increase (all $p<0.05)$ in $\mathrm{FE}_{\mathrm{Na}}$ was observed at the reperfusion phase in the L-NAME-CONTROL and also in the PAG-administered groups in both the WKY and L-NAME-induced hypertensive groups (WKY+PAG and L-NAME+PAG) when they were compared to their respective groups at the pre-ischemia phase. However, the rest of the groups did not show any significant changes (all $p>0.05$ ) in $\mathrm{FE}_{\mathrm{Na}}$ at the reperfusion phase when they were compared to their respective groups at the pre-ischemia phase. At the reperfusion phase in the WKY groups, $\mathrm{FE}_{\mathrm{Na}}$ was significantly reduced $(p<0.05)$ in the WKY+NaHS group when compared to the WKY+PAG group at the same phase. Similarly, in L-NAME-induced hypertensive groups, $\mathrm{FE}_{\mathrm{Na}}$ was also found to be significantly reduced $(p<0.05)$ in the L-NAME+NaHS group when compared to the L-NAME-CONTROL and WKY+PAG groups at the reperfusion phase. No significant changes (all $p>0.05$ ) in $\mathrm{FE}_{\mathrm{K}}$ or plasma creatinine were observed in either the WKY or the L-NAME-induced hypertensive rats at the reperfusion phase when they were compared to their respective groups at the pre-ischemia phase. However, $\mathrm{FE}_{\mathrm{K}}$ and plasma creatinine were found to be significantly reduced $(p<0.05)$ in the LNAME+NaHS group when compared to the L-NAME-CONTROL and L-NAME+PAG groups. It was also observed that $\mathrm{FE}_{\mathrm{Na}}, \mathrm{FE}_{\mathrm{K}}$ and plasma creatinine were significantly high $(p<0.05)$ in L-NAME-induced hypertensive rats when compared to WKY rats. 

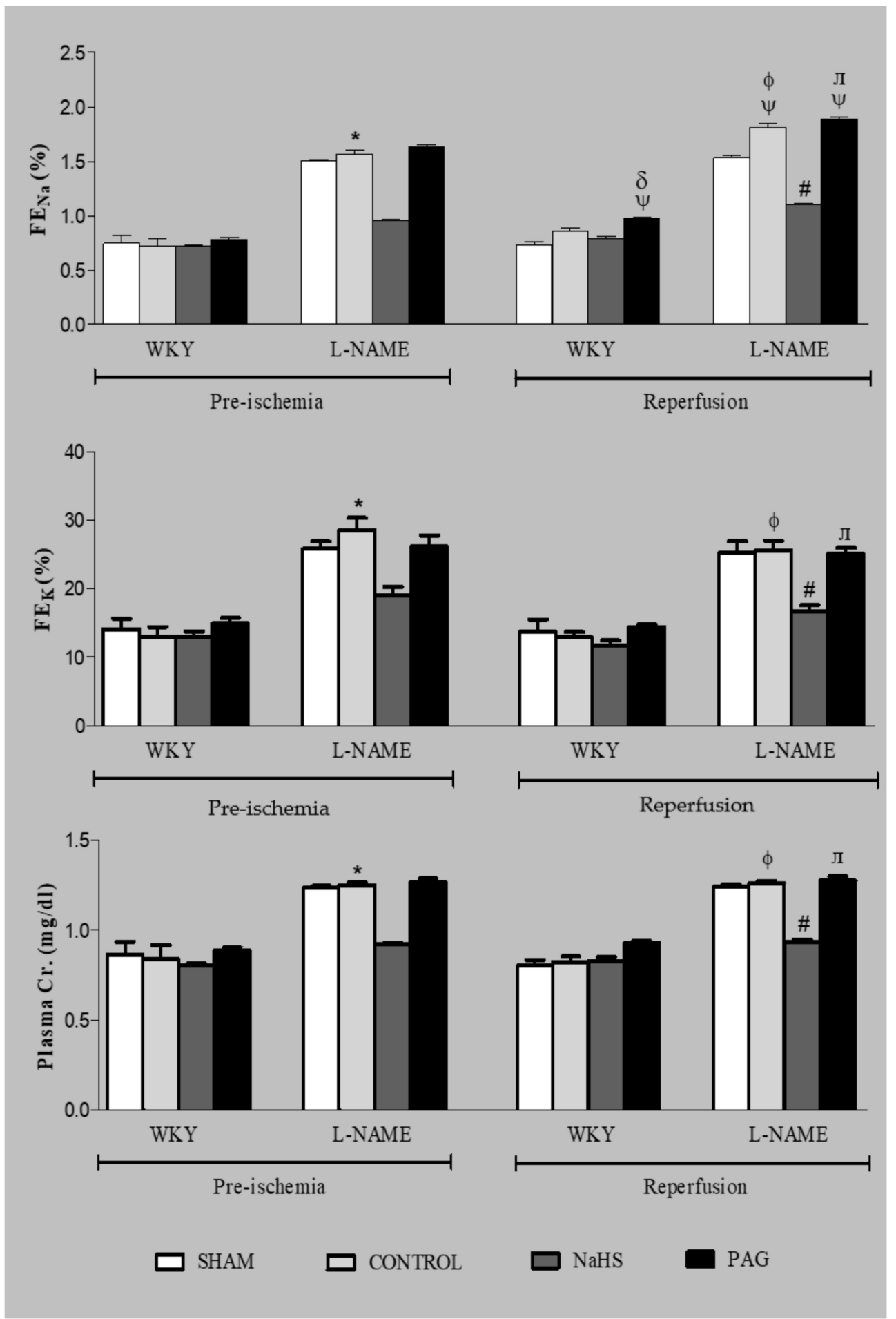

Figure 3. $\mathrm{FE}_{\mathrm{Na}}, \mathrm{FE}_{\mathrm{K}}$ and plasma creatinine measurements for different experimental groups of WKY and L-NAME rats before and after ischemia $(n=6)$. Data were analysed using one-way ANOVA followed by Bonferroni's post hoc test. ${ }^{\Psi}$ $p<0.05$ vs. pre-ischemic phase of respective groups; ${ }^{*} p<0.05$ vs. WKY-CONTROL at pre-ischemic phase; ${ }^{\phi} p<0.05$ vs. WKY-CONTROL at reperfusion phase; ${ }^{\delta} p<0.05$ vs. WKY+NaHS at reperfusion phase; \# $p<0.05$ vs. L-NAMECONTROL at reperfusion phase; ${ }^{\pi} p<0.05$ vs. L-NAME+NaHS at reperfusion phase. $\mathrm{FE}_{\mathrm{Na}}=$ fractional excretion of sodium, $\mathrm{FE}_{\mathrm{K}}=$ fractional excretion of potassium, $\mathrm{Cr}$. = creatinine, PAG = dL-propargylglycine, WKY = Wistar Kyoto rats, L-NAME = L-nitro-methyl-arginine-ester. 


\subsection{Oxidative Stress Markers at the Pre-Ischemia and Reperfusion Phases}

Oxidative stress markers such as MDA, T-SOD and GSH were also measured at the pre-ischemia and reperfusion phases (Figure 4). No significant changes $(p>0.05)$ were observed in oxidative stress markers in the SHAM groups in which no ischemia was induced. A significant increase $(p<0.05)$ in MDA concentration was observed only in the WKY-CONTROL and L-NAME-CONTROL groups at the reperfusion phase when compared to their respective groups at the pre-ischemia phase. Pre-treatment with NaHS and administration of PAG did not exert any significant effect on the MDA concentration at the reperfusion phase when compared to their respective groups at the pre-ischemia phase. A significant decrease (all $p<0.05$ ) in T-SOD level was observed at the reperfusion phase in CONTROL and PAG-administered groups both in WKY and L-NAME-induced hypertensive rats when compared to their respective groups at the pre-ischemia phase. However, in groups pre-treated with NaHS, the T-SOD level was found to be significantly high $(p<0.05)$ at the reperfusion phase in both WKY and L-NAME-induced hypertensive groups (WKY+NaHS and L-NAME+NaHS) when compared to their CONTROL groups (WKY-CONTROL and L-NAME-CONTROL) and to PAG-administered groups (WKY+PAG and L-NAME+PAG) at the same phase. No significant changes (all $p>0.05$ ) in GSH concentration were observed at the reperfusion phase in any WKY and L-NAME-induced hypertensive groups when they were compared to their respective groups at the preischemia phase. However, it was observed that GSH concentration at the reperfusion phase was significantly high $(p<0.05)$ in the WKY+NaHS group compared to the WKY+PAG group at the same phase. Similarly, GSH concentration was also significantly high $(p<0.05)$ at the reperfusion phase in the L-NAME+NaHS group when compared to the L-NAMECONTROL and L-NAME+PAG groups. It was observed that MDA concentration was significantly higher $(p<0.05)$ and T-SOD and GSH levels were significantly lower (all $p<0.05)$ in L-NAME-induced hypertensive rats when compared to WKY rats.

3.9. ICAM-1 Expression and NF-kB Concentration at the Pre-Ischemia and Reperfusion Phases in Plasma and Kidney Tissues of Different Groups

Levels of ICAM-1 and NF-kB concentration were also measured at the pre-ischemia and reperfusion phases in both WKY and L-NAME-induced hypertensive groups, as shown in Figure 5A,B. No significant differences $(p>0.05)$ in either ICAM-1 levels or NF$\mathrm{kB}$ concentration were noticed in the SHAM groups of either WKY or L-NAME-induced hypertensive groups in which no ischemia was induced. However, significant increases (all $p<0.05$ ) in ICAM-1 levels and NF-kB concentration were observed in both WKY and L-NAME-induced hypertensive groups at the reperfusion phase when they were compared to their respective groups at the pre-ischemia phase, except the NaHS treatment groups (WKY+NaHS and L-NAME+NaHS), in which there was no significant increase $(p>0.05)$ in NF-kB concentration at the reperfusion phase compared to their respective groups at the pre-ischemia phase. Pre-treatment with NaHS significantly reduced (all $p<0.05)$ levels of ICAM-1 and concentrations of NF-kB in both WKY and L-NAMEinduced hypertensive rats (WKY+NaHS and L-NAME+NaHS) at the reperfusion phase when they were compared to their respective CONTROL groups (WKY-CONROL and L-NAME-CONTROL) at the same phase. Similarly, administration of PAG caused significant increases $(p<0.25)$ in ICAM-1 expression in both WKY and L-NAME-induced hypertensive groups (WKY+PAG and L-NAME+PAG) at the reperfusion phase when they were compared to their respective control groups (WKY-CONTROL and L-NAMECONTROL) and also to the NaHS-treated groups (WKY+NaHS and L-NAME+NaHS) at the same phase. Similarly, in PAG-administered groups, significant increases $(p<0.05)$ in NF-kB concentration were observed in both the WKY and L-NAME-induced groups (WKY+PAG and L-NAME+PAG) at the reperfusion phase compared to their respective NaHS-treated groups (WKY+NaHS and L-NAME+NaHS) at the same phase. It was noticed that the ICAM-1 levels and NF-kB concentration were significantly high $(p<0.05)$ in L-NAME-induced hypertensive rats when compared to WKY rats. 

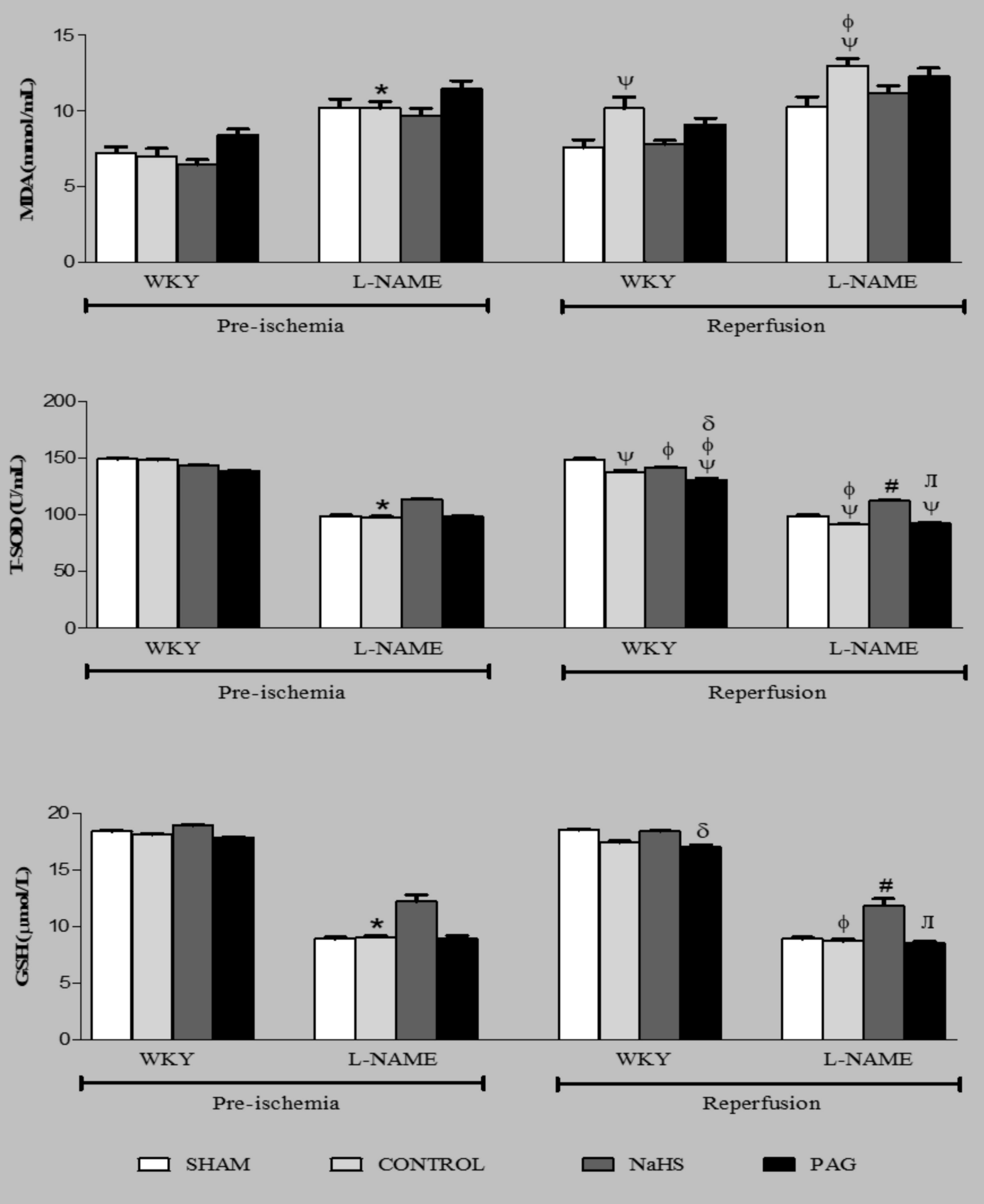

Figure 4. MDA, T-SOD and GSH concentrations in different experimental groups of WKY and L-NAME rats before and after ischemia $(n=6)$. Data were analysed using one-way ANOVA followed by Bonferroni's post hoc test. ${ }^{\Psi} p<0.05$ vs. preischemic phase of respective groups; ${ }^{*} p<0.05$ vs. WKY-CONTROL at pre-ischemic phase; ${ }^{\phi} p<0.05$ vs. WKY-CONTROL at reperfusion phase; ${ }^{\delta} p<0.05$ vs. WKY $+\mathrm{NaHS}$ at reperfusion phase; ${ }^{\#} p<0.05$ vs. L-NAME-CONTROL at reperfusion phase; ${ }^{\text {л }} p<0.05$ vs. L-NAME+NaHS at reperfusion phase. MDA $=$ malondialdehyde, T-SOD $=$ total superoxide dismutase, $\mathrm{GSH}=$ glutathione, $\mathrm{PAG}=\mathrm{dL}$-propargylglycine, WKY = Wistar Kyoto rats, L-NAME = L-nitro-methyl-arginine-ester. 


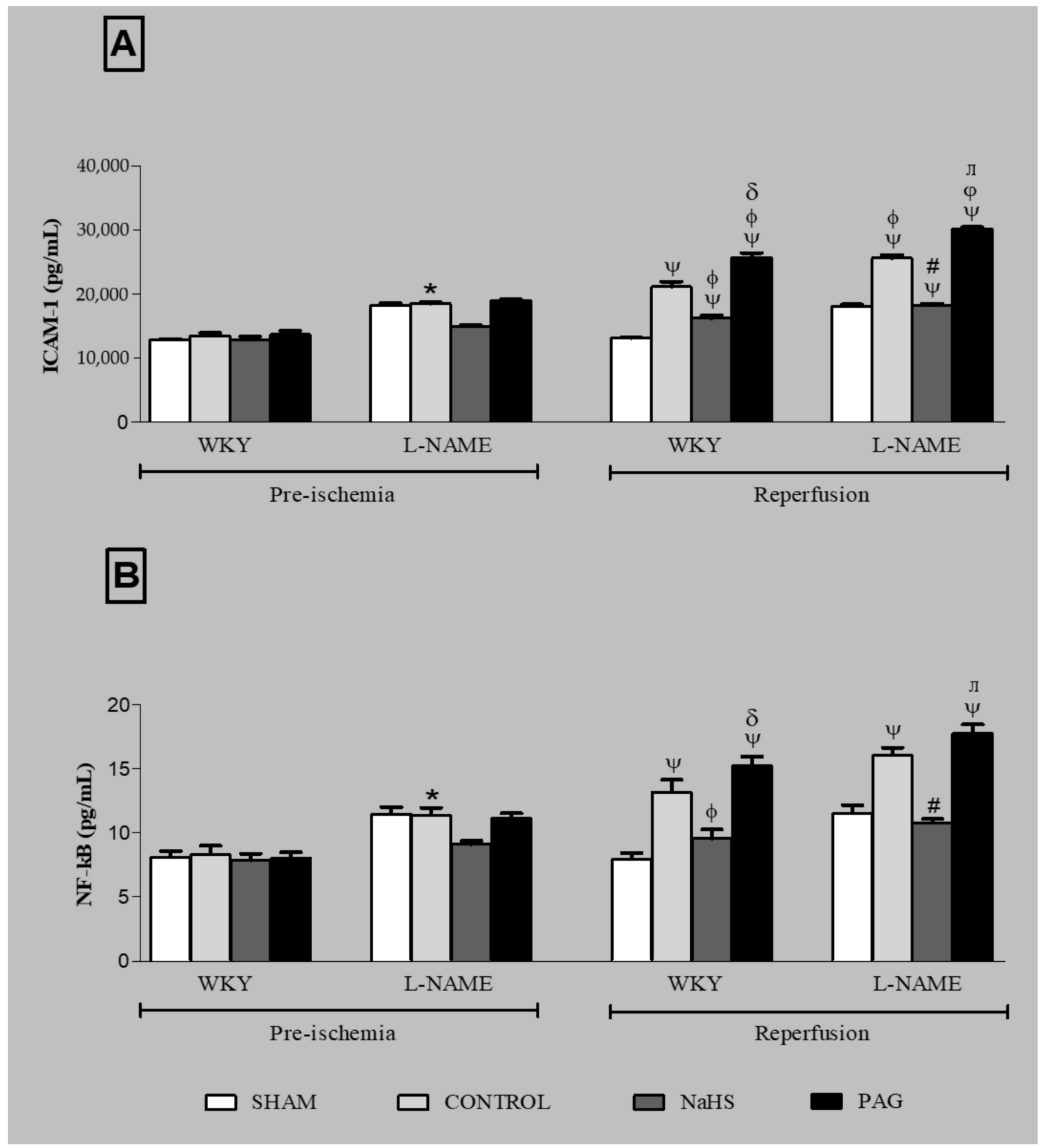

Figure 5. ICAM-1 concentration (A) and NF-kB concentration (B) in the kidney tissues of different experimental groups of WKY and L-NAME rats before and after ischemia $(n=6)$. Data were analysed using one-way ANOVA followed by Bonferroni's post hoc test. ${ }^{\Psi} p<0.05$ vs. pre-ischemic phase of respective groups; ${ }^{*} p<0.05$ vs. WKY-CONTROL at pre-ischemic phase; ${ }^{\phi} p<0.05 \mathrm{vs}$. WKY-CONTROL at reperfusion phase; $\delta p<0.05 \mathrm{vs}$. WKY+NaHS at reperfusion phase; ${ }^{\#} p<0.05$ vs. L-NAME-CONTROL at reperfusion phase; ${ }^{\pi} p<0.05$ vs. L-NAME+NaHS at reperfusion phase. ICAM1 = intercellular adhesion molecule-1. NF-kB = nuclear factor-kappa B, PAG = dL-propargylglycine, WKY = Wistar Kyoto rats, L-NAME = L-nitro-methyl-arginine-ester. 
Levels of ICAM-1 and NF-kB concentration were also measured at the pre-ischemia and reperfusion phases in the kidney tissues of both WKY and L-NAME-induced hypertensive groups, as shown in Figure 6A,B. The trends for the levels of ICAM-1 and NF-kB concentrations in the kidney tissue were the same as those in the plasma samples of the different groups. Induction of reperfusion significantly raised $(p<0.05)$ the levels of ICAM1 in the kidneys of control and PAG-treated animals in the WKY and L-NAME groups, while chronic treatment with $\mathrm{H}_{2} \mathrm{~S}$ donation to animals in the WKY and L-NAME groups significantly reduced $(p<0.05)$ the ICAM-1 levels in kidney tissue at the reperfusion phase when compared to the control WKY and control L-NAME groups at the same phase, as shown in Figure 6A.

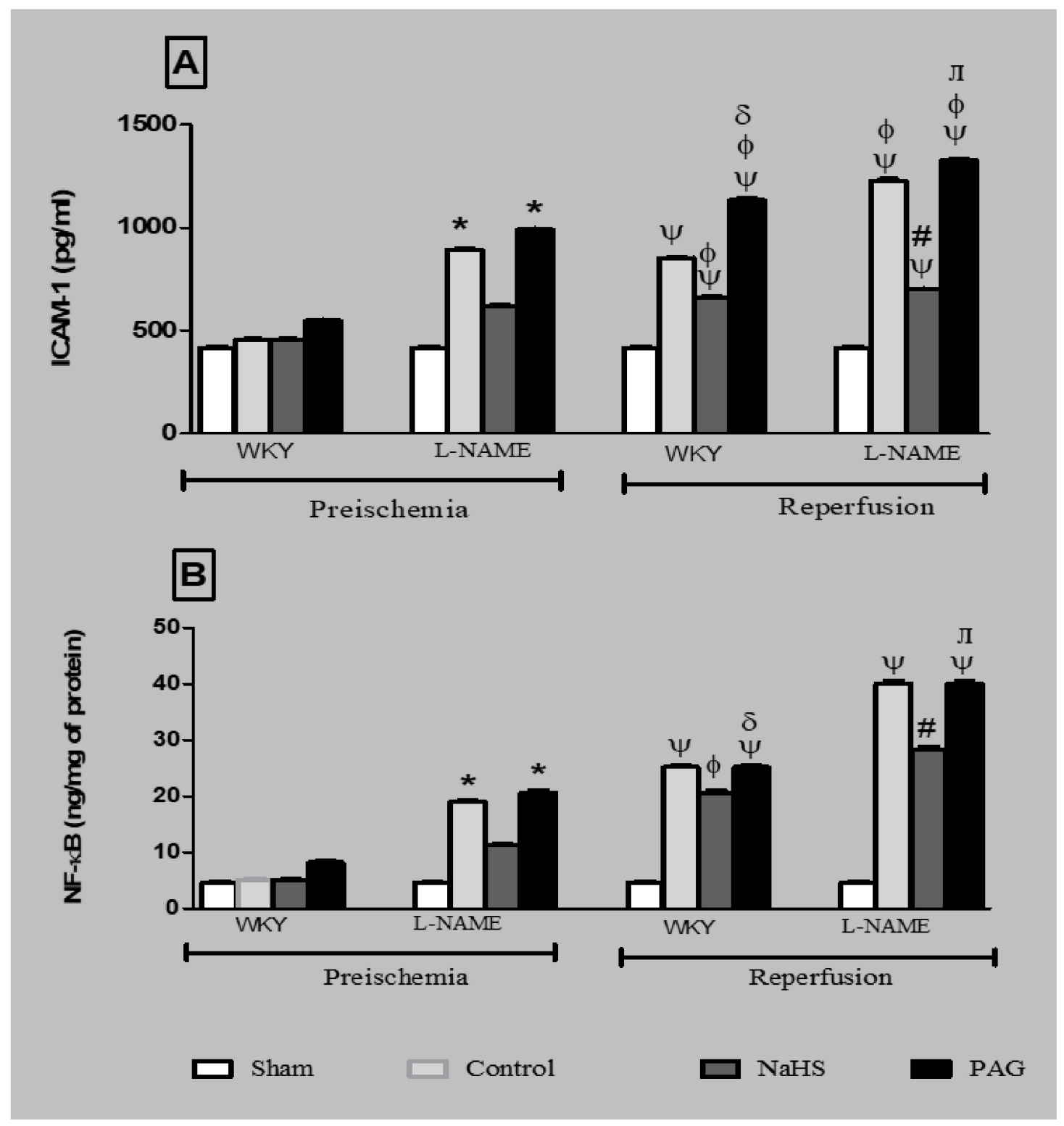

Figure 6. (A) ICAM-1 concentration and (B) NF-kB concentration in kidney tissues of different experimental groups of WKY and L-NAME rats before and after ischemia $(n=6)$. Data were analysed using one-way ANOVA followed by Bonferroni's post hoc test. ${ }^{\Psi} p<0.05$ vs. pre-ischemic phase of respective groups; ${ }^{*} p<0.05$ vs. WKY-CONTROL at pre-ischemic phase; ${ }^{\phi} p<0.05$ vs. WKY-CONTROL at reperfusion phase; $\delta p<0.05$ vs. WKY+NaHS at reperfusion phase; ${ }^{\#} p<0.05$ vs. L-NAME-CONTROL at reperfusion phase; ${ }^{\pi} p<0.05$ vs. L-NAME+NaHS at reperfusion phase. ICAM1 = intercellular adhesion molecule-1; NF-kB = nuclear factor-kappa B; PAG = dL-propargylglycine; WKY = Wistar Kyoto rats; L-NAME = L-nitro-methyl-arginine-ester. 
Induction of reperfusion significantly raised $(p<0.05)$ the levels of NF-кB in the kidneys of control and PAG-treated animals in the WKY and L-NAME groups, while chronic treatment with $\mathrm{H}_{2} \mathrm{~S}$ donation to the animals in the WKY and L-NAME groups significantly reduced $(p<0.05)$ the NF-KB levels in the kidney tissue in the reperfusion phase compared to control WKY and control L-NAME groups at the same phase, as shown in Figure 6B.

3.10. Histopathology of Kidney Tissue for All Animals in the WKY and L-NAME Groups (Sham, Control, NAHS and PAG)

The renal tissue of control rats showed normal glomerulus architecture and distal and proximal convoluted tubules of the nephron, as shown in Figure 7A. The renal tissue of ischemia reperfusion (I/R) affected the rats' kidneys and indicated the presence of swollen renal tubules, with epithelial denudation of the basement membrane and a few necrotic tubules, as highlighted by the white arrows in Figure 7B. Renal tissue of sham-control rats showed a normal glomerulus and tubular architecture, as shown in Figure $7 \mathrm{C}$. The renal tissue of $\mathrm{H}_{2} \mathrm{~S}$-treated rats showed normal renal tissue architecture, as shown in Figure 7D. Normal tubular morphology, still with a few swollen tubules, was observed, but the structure of renal tissue was almost similar to that of sham-control rats (C), without any glomerular hypertrophy or necrotic tubules, as shown in Figure 7E.

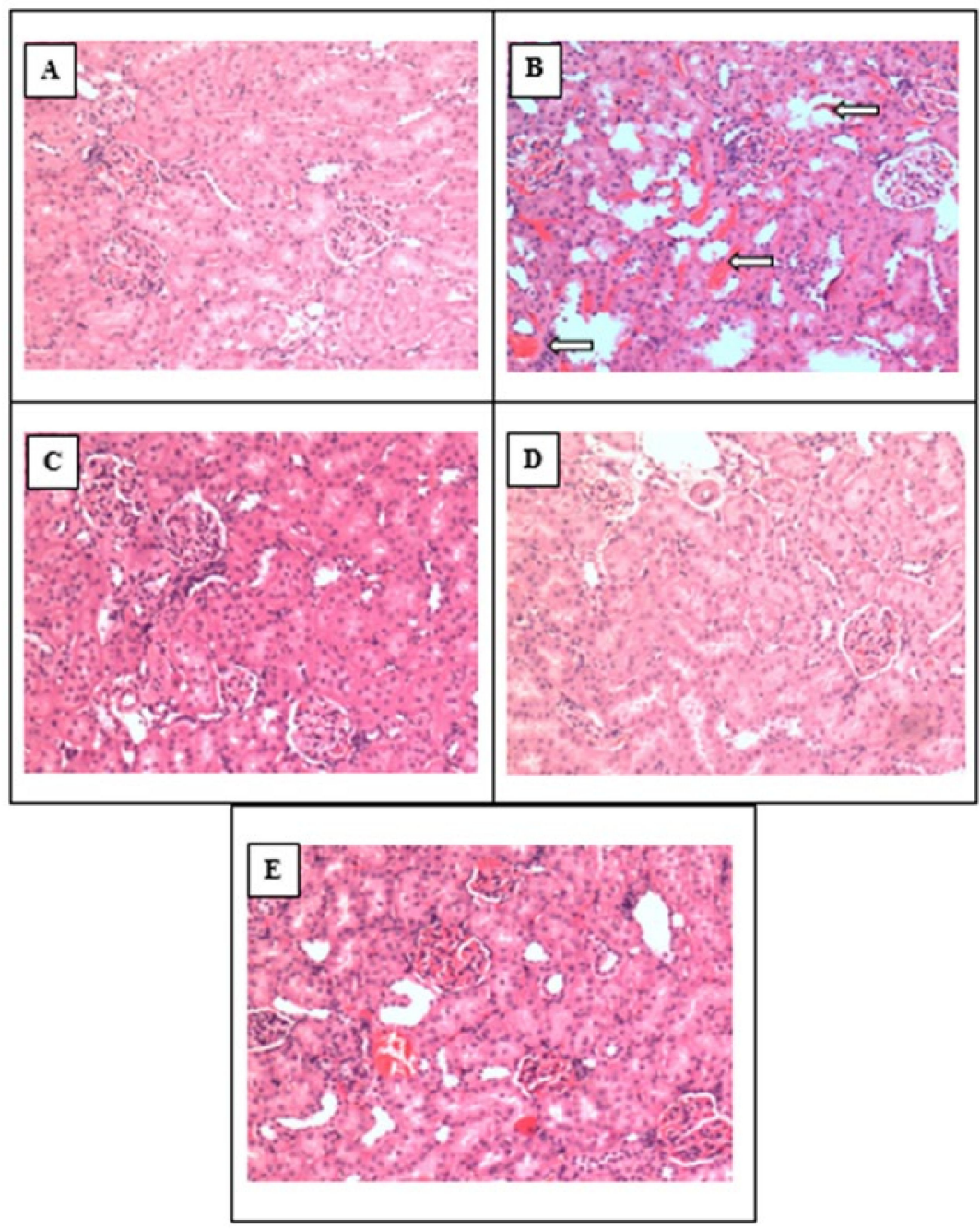

Figure 7. Histopathology study of kidneys from (A) control, (B) renal ischemic-reperfusion injury, (C) sham-control, (D) $\mathrm{H}_{2} \mathrm{~S}$-treated and (E) renal ischemic-reperfusion injury treated with $\mathrm{H}_{2} \mathrm{~S}$ rats (magnification: $10 \times$ ). 


\section{Discussion}

The present study investigated the effect of exogenous administration of $\mathrm{H}_{2} \mathrm{~S}$ in the attenuation of the extent of IRI in normotensive and L-NAME-induced hypertensive rats. This study proposed that exogenous administration of $\mathrm{H}_{2} \mathrm{~S}$ would attenuate the extent of IRI through its antioxidant mechanisms by enhancing antioxidant markers and through its anti-inflammatory mechanism by reducing I-CAM expression and NF-kB concentration in both models of rats. The present study resulted in two key findings: first, exogenous administration of $\mathrm{H}_{2} \mathrm{~S}$ reduced the extent of IRI by improving antioxidant markers such as SOD and GSH and attenuating the MDA in normotensive and L-NAME-induced hypertensive rats. The second novel observation was that the exogenous administration of $\mathrm{H}_{2} \mathrm{~S}$ attenuated the extent of IRI by reducing I-CAM expression and NF-kB concentration due to its antiinflammatory mechanism in normotensive and L-NAME-induced hypertensive rats.

Inflammation has been reported to be involved in the pathogenesis of injuries induced by ischemia reperfusion, and the infiltration of neutrophils is a main contributor in this regard [47], further increasing the severity of IRI by producing more ROS [48]. Reperfusion of blood induces the production of ROS, which play a major role in the sequence of IRI [49-52] by inducing the expression of ICAM-1 via NF-kB activation [53]. To the best of our knowledge, there is no information available regarding the antioxidant and anti-inflammatory potential of chronic treatment with an $\mathrm{H}_{2} \mathrm{~S}$ donor (NaHS) on ICAM-1 expression and NF-kB activation in normotensive and hypertensive models following renal IRI.

In the present study, L-NAME rats showed an increase in MAP that was comparable to results reported previously [54-56]. Increased MAP in L-NAME rats was assumed to be due, in part, to its eNOS- and nNOS-inhibiting properties, which can result in NO deficiency and stimulation of the sympathetic nervous system [57]. Moreover, activation of the renin angiotensin system (RAS) has also been documented in an L-NAME-induced hypertension model [58]. However, when L-NAME groups of rats were pre-treated with an $\mathrm{H}_{2} \mathrm{~S}$ donor (NaHS), a drop in MAP was observed. This reduction in blood pressure may have been due to the vasodilating properties of $\mathrm{H}_{2} \mathrm{~S}[25,59]$. The anti-hypertensive property of $\mathrm{H}_{2} \mathrm{~S}$ in L-NAME-induced hypertension is well-documented and in line with previously reported data [27]. Increased HR in L-NAME-induced hypertension was also observed, and it has been reported that elevated sympathetic activity and oxidative stress may be responsible for increased HR in L-NAME-induced hypertension [56]. Similarly, increases in $\mathrm{FE}_{\mathrm{Na}}$ and $\mathrm{FE}_{\mathrm{K}}$ were observed in L-NAME-induced hypertensive rats, which is coherent with previously reported data [60]. These increases may have been due to glomerular injury and impaired renal sodium and potassium handling from chronic inhibition of NOS by L-NAME treatment, as L-NAME has also previously been reported as a causative agent for glomerular injury [61]. Surprisingly, decreases in both $\mathrm{FE}_{\mathrm{Na}}$ and $\mathrm{FE}_{\mathrm{K}}$ were found in the present study when the L-NAME group was pre-treated with NaHS. Reduced tubular damage in the kidneys has been reported following $\mathrm{H}_{2} \mathrm{~S}$ supplementation [62]. An important renal functional parameter, $\mathrm{Cr} . \mathrm{Cl}$, which is an indirect indicator of the glomerular filtration rate, was also ameliorated in all L-NAME-induced hypertensive groups, which is in line with an earlier study [63].

The physiological concentration of $\mathrm{H}_{2} \mathrm{~S}$ in rat serum is $46 \mu \mathrm{M}$ [59], while other studies have reported a range of 50-160 $\mu \mathrm{M}$ in humans, rats and bovines [64,65]. In the present study, pre-treatment with NaHS in the WKY group for 35 days increased the plasma concentration of $\mathrm{H}_{2} \mathrm{~S}$ but, in contrast, when WKY rats were administered with PAG, a reduction in plasma $\mathrm{H}_{2} \mathrm{~S}$ concentration was observed. This finding is well-supported by previous studies [66-69]. Furthermore, L-NAME-induced hypertensive groups showed reductions in plasma $\mathrm{H}_{2} \mathrm{~S}$ concentrations, but this was surprisingly improved following $\mathrm{NaHS}$ treatment. L-NAME is reported to cause inhibition of CSE gene expression, which in return reduces the endogenous production of $\mathrm{H}_{2} \mathrm{~S}$ [27].

To the best of our knowledge, there is no information available regarding RCBP data for renal IRI. RCBP was reduced in all groups of WKY and L-NAME-induced hypertensive rats at the reperfusion phase, except in sham groups in which no ischemia was induced. 
The present findings are in accordance with earlier studies that have reported that renal blood flow is reduced after renal IRI [34,44]. However, when the L-NAME group was pretreated with NaHS, the RCBP was increased, which was possibly due to the vasodilatory effect of $\mathrm{H}_{2} \mathrm{~S}$ [59]. It is also likely that there was $\mathrm{H}_{2} \mathrm{~S}$-mediated enhancement of preglomerular arterial vasodilation and renal blood flow [70]. Another reason may have been the upregulation of the $\mathrm{CSE} / \mathrm{H}_{2} \mathrm{~S}$ pathway in the kidney due to exogenous administration of $\mathrm{H}_{2} \mathrm{~S}$, as reported previously [71]. Increases in kidney weight and kidney index (KI) were observed in both WKY and L-NAME-induced hypertensive rats. The present findings are supported by earlier studies, which have reported that increases in kidney weight are due to reflection of oedema, obstruction of peritubular capillaries due to leukocyte plugging and neutrophil infiltration into the injury site after renal IRI [72-74]. However, groups that were pre-treated with NaHS did not show such increases in either kidney weight or KI after renal IRI.

During the acute experiment, following IRI, only an increase in $\mathrm{FE}_{\mathrm{Na}}$ was observed without any change in $\mathrm{FE}_{\mathrm{K}}$ or plasma creatinine in the L-NAME-induced hypertensive groups, while NaHS treatment in the L-NAME group improved the $\mathrm{FE}_{\mathrm{Na}}$ after renal IRI. Elevated $\mathrm{FE}_{\mathrm{Na}}$ is due to impaired sodium-handling capacity in renal tubules after renal IRI. This finding is in line with a previously reported study that found that renal tubular cells are particularly vulnerable to IRI, which causes higher levels of sodium excretion [34].

Oxidative stress is an important feature in IRI that is followed by free-radical production [75] and renal damage characterized by lipid peroxidation of polyunsaturated fatty acids [76]. Lipid peroxidation involves the production of the highly toxic reactive aldehydic metabolite, MDA [77]. In the present study, increased MDA concentrations were observed after IRI in untreated control groups of both WKY and L-NAME rats. This finding is consistent with previous published studies on the same IRI animal model [78-83]. Interestingly, increased levels of MDA were observed following NaHS treatment. Furthermore, reductions in both T-SOD and GSH levels were observed in both WKY and L-NAME-induced hypertensive groups, except the NaHS-treated groups, after renal IRI. Supplementation of $\mathrm{H}_{2} \mathrm{~S}$ increased both T-SOD and GSH levels in both groups after renal IRI. The increased MDA and decreased T-SOD levels indicate the imbalance between the antioxidant and pro-oxidants induced by renal IRI. Pre-treatment with NaHS improved the levels of all oxidative stress markers, including MDA, T-SOD and GSH levels, likely due to the antioxidant and scavenging properties of $\mathrm{H}_{2} \mathrm{~S}$, which is known to scavenge superoxide anions [84] and peroxynitrite [85]. On the other hand, when both groups of WKY and L-NAME rats were administrated with PAG, they showed decreased levels of T-SOD and GSH after renal IRI. The possible reason for the reduction in these two antioxidant enzymes is that PAG reduces the endogenous concentration of $\mathrm{H}_{2} \mathrm{~S}$; thus, the kidney becomes more capable of rendering oxidative stress. In short, L-NAME-induced hypertensive rats showed high levels of oxidative stress following ischemia. This finding is well-documented and supported by previously reported data [36,37].

One important finding of the study related to exploring the levels of ICAM-1 and NF-kB following renal IRI in plasma and kidney tissue to evaluate the events happening in the plasma and kidney tissue. Massive accumulation and infiltration of leukocytes occurs in IRI $[86,87]$. The results of the present study showed increased ICAM-1 expression in both WKY and L-NAME-induced hypertensive rats after renal IRI, except in SHAM groups that were not subjected to renal ischemia. The present findings are consistent with earlier studies [32,44]. Increased concentrations of ICAM-1 in the plasma and kidney tissue indicate the involvement of inflammation in the present model of renal IRI. However, when the same group model was pre-treated with NaHS, it reduced ICAM-1 concentration in the kidney after renal IRI. The present findings are in line with earlier published studies, which have also reported that exogenous administration of $\mathrm{H}_{2} \mathrm{~S}$ reduces ICAM- 1 expression in renal IRI. [32,33,35]. However, administration of PAG increased ICAM-1 expression in both groups. To the best of our knowledge, there are no available data regarding the effect of PAG on ICAM-1 expression in a renal IRI model for normotensive as well as L-NAME-induced 
hypertensive rats. However, overexpression of ICAM-1 has been reported following PAG administration in hepatic [69] and myocardial IRI models [68]. The present findings regarding overexpression of ICAM-1 through decreased endogenous concentration of $\mathrm{H}_{2} \mathrm{~S}$ by PAG administration strengthen the notion that decreased endogenous concentration of $\mathrm{H}_{2} \mathrm{~S}$ renders the reperfused kidney more prone to the consequences of IRI and that supplementation of $\mathrm{H}_{2} \mathrm{~S}$ reduces the severity of IRI due to its anti-inflammatory potential, as evidenced by decreased expression of ICAM- 1 in the plasma and kidney.

Increases in NF-kB concentrations in plasma and kidneys were also observed in both WKY and L-NAME-induced hypertensive rats after renal IRI, except in SHAM groups in which no ischemia was induced. Increased NF-kB concentration has also been reported previously in renal IRI models [32,88-93]. Pre-treatment with NaHS reduced NF-kB concentration after IRI in normotensive and hypertensive rats both globally and locally in the kidney. Decreased NF-kB concentration has also been reported in a renal IRI model following topical administration of NaHS onto the kidneys [32]. However, NF-kB concentration was increased after administration of PAG. Since, ROS have been reported to induce NF-kB activation, it can therefore be concluded from the present findings that $\mathrm{H}_{2} \mathrm{~S}$ scavenged ROS through its antioxidant potential [94]. The interesting and novel finding of the present study was the inhibition of NF-kB activation by NaHS treatment, which in response reduced the expression of ICAM-1. PAG administration also confirmed that a decreased concentration of $\mathrm{H}_{2} \mathrm{~S}$ is endogenously responsible for the increased NF-kB concentration and overexpression of ICAM-1 in normotensive and hypertensive rats following renal IRI. Histopathological examination of kidney tissue treated with NaHS also indicated normal tubular morphology, still with a few swollen tubules, but the structure of the renal tissue was almost similar to that of sham-control rats, without any glomerular hypertrophy or necrotic tubules.

\section{Conclusions}

Taken together, the results of this study indicate that exogenous administration of $\mathrm{H}_{2} \mathrm{~S}$ reduced the extent of IRI by improving antioxidant markers, such as T-SOD and GSH, and attenuating the MDA in normotensive and L-NAME-induced hypertensive rats. In addition to this, exogenous administration of $\mathrm{H}_{2} \mathrm{~S}$ attenuated the extent of IRI by reducing I-CAM expression and NF-kB concentration both locally in the kidney and systemically in normotensive and L-NAME-induced hypertensive rats due to its anti-inflammatory mechanism. The outcome of the present study will help in providing renal protection following renal IRI and will reduce the chances of transplanted kidney injuries. Exogenous administration of $\mathrm{H}_{2} \mathrm{~S}$ not only provides renal protection in IRI but also improves the excretory function and morphology of the kidney.

Author Contributions: A.A., H.A.R. and E.J.J.: Conceived and designed the experiments; S.F.H., T.Y.C. and A.A. performed the experiments; T.Y.C. and C.-Y.G. analysed the data; H.A.R., M.A.S., C.-Y.G. and T.Y.C. contributed reagents/materials/analysis tools; S.F.H., A.A. and H.A.R. wrote the paper. All authors have read and agreed to the published version of the manuscript.

Funding: The Institute of Postgraduate Studies (IPS), Universiti Sains Malaysia, is acknowledged for the provision of Graduate Assistantship (GA) to Syed Fayaz Ul Haq Hashmi (Matric no. PFM0008/14(R)), as is the Research and Creativity and Management Office (RCMO), Universiti Sains Malaysia.

Institutional Review Board Statement: All the experimental procedures were approved by the Universiti Sains Malaysia Animal Ethics committee with approval letter reference no. USM/Animal Ethics Approval/2015/(95) (649).

Informed Consent Statement: Research procedure and use of animals in this study were approved by animal ethics committee, School of Pharmaceutical Sciences, Universiti Sains Malaysia with approval letter reference no. USM/Animal Ethics Approval/2015/(95) (649). 
Conflicts of Interest: The authors declare no conflict of interest. The funders had no role in the design of the study; in the collection, analyses, or interpretation of data; in the writing of the manuscript, or in the decision to publish the results.

Dedication: This manuscript is dedicated to the late Munavvar Zubaid Abdul Sattar. At the School of Pharmacy, Universiti Sains Malaysia, he created a unique research environment in the area of kidney and cardiovascular diseases to which national and international researchers were welcomed. Students and fellows were nurtured in their research development through his support and gentle guidance and many of these individuals have gone on to attain senior academic positions which is a hallmark of his contribution.

\begin{tabular}{ll}
\multicolumn{2}{l}{ Abbreviations } \\
H2S & Hydrogen sulphide \\
IRI & Ischemia-reperfusion injury \\
ICAM & Intracellular adhesion molecule \\
PAG & dL-propargylglycine \\
NRF & Non-renal failure \\
g & grams \\
L-NAME & $N_{\omega}$-Nitro-L-arginine methyl ester hydrochloride \\
SOD & Superoxide dismutase \\
MDA & Malondialdehyde \\
TAOC & Total antioxidant capacity \\
GSH & Glutathione \\
NF-KB & Nuclear factor-kappa B \\
KI & Kidney index \\
RCBP & Renal cortical blood perfusion \\
FeNa & Fractional excretion of sodium \\
FeK & Fractional excretion of potassium \\
SBP & Systolic blood pressure \\
DBP & Diastolic blood pressure \\
HR & Heart rate \\
PWV & Pulse-wave velocity \\
NOS & Nitric oxide synthase \\
BW & Body weight \\
KW & Kidney weight \\
&
\end{tabular}

\section{References}

1. Lindner, J.R.; Coggins, M.P.; Kaul, S.; Klibanov, A.L.; Brandenburger, G.H.; Ley, K. Microbubble persistence in the microcirculation during ischemia/reperfusion and inflammation is caused by integrin-and complement-mediated adherence to activated leukocytes. Circulation 2000, 101, 668-675. [CrossRef]

2. Kurose, I.; Anderson, D.C.; Miyasaka, M.; Tamatani, T.; Paulson, J.C.; Todd, R.F.; Rusche, J.R.; Granger, D. Molecular determinants of reperfusion-induced leukocyte adhesion and vascular protein leakage. Circ. Res. 1994, 74, 336-343. [CrossRef]

3. Jaeschke, H. Mechanisms of Liver Injury. II. Mechanisms of neutrophil-induced liver cell injury during hepatic ischemiareperfusion and other acute inflammatory conditions. Am. J. Physiol. Gastrointest. Liver Physiol. 2006, 290, G1083-G1088. [CrossRef]

4. Steinhoff, G.; Behrend, M.; Schrader, B.; Duijvestijn, A.; Wonigeit, K. Expression patterns of leukocyte adhesion ligand molecules on human liver endothelia. Lack of ELAM-1 and CD62 inducibility on sinusoidal endothelia and distinct distribution of VCAM-1, ICAM-1, ICAM-2, and LFA-3. Am. J. Pathol. 1993, 142, 481.

5. Vollmar, B.; Glasz, J.; Menger, M.D.; Messmer, K. Leukocytes contribute to hepatic ischemia/reperfusion injury via intercellular adhesion molecule-1-mediated venular adherence. Surgery 1995, 117, 195-200. [CrossRef]

6. Collins, T.; Read, M.; Neish, A.; Whitley, M.; Thanos, D.; Maniatis, T. Transcriptional regulation of endothelial cell adhesion molecules: NF-kappa B and cytokine-inducible enhancers. FASEB J. 1995, 9, 899-909. [CrossRef]

7. Nichols, T.C. NF-kB and reperfusion injury. Drug News Perspect 2004, 17, 99-104. [CrossRef] [PubMed]

8. Chen, A.C.; Arany, P.R.; Huang, Y.-Y.; Tomkinson, E.M.; Sharma, S.K.; Kharkwal, G.B.; Saleem, T.; Mooney, D.; Yull, F.E.; Blackwell, T.S. Low-level laser therapy activates NF-kB via generation of reactive oxygen species in mouse embryonic fibroblasts. PLoS ONE 2011, 6, e22453. [CrossRef] [PubMed]

9. Rhee, S.G. Redox signaling: Hydrogen peroxide as intracellular messenger. Exp. Mol. Med. 1999, 31, 53-59. [CrossRef] [PubMed] 
10. Rahman, A.; Anwar, K.N.; True, A.L.; Malik, A.B. Thrombin-induced p65 homodimer binding to downstream NF- $\mathrm{kB}$ site of the promoter mediates endothelial ICAM-1 expression and neutrophil adhesion. J. Immunol. 1999, 162, 5466-5476. [PubMed]

11. Singh, D.; Chopra, K. The effect of naringin, a bioflavonoid on ischemia-reperfusion induced renal injury in rats. Pharmacol. Res. 2004, 50, 187-193. [CrossRef]

12. Singh, D.; Chander, V.; Chopra, K. Protective effect of catechin on ischemia-reperfusion-induced renal injury in rats. Pharm. Rep 2005, 57, 70-76.

13. Szabó, C. Hydrogen sulphide and its therapeutic potential. Nat. Rev. Drug Discov. 2007, 6, 917-935. [CrossRef]

14. Blackstone, E.; Morrison, M.; Roth, M.B. H2S induces a suspended animation-like state in mice. Science 2005, 308, 518. [CrossRef]

15. Zanardo, R.C.; Brancaleone, V.; Distrutti, E.; Fiorucci, S.; Cirino, G.; Wallace, J.L. Hydrogen sulfide is an endogenous modulator of leukocyte-mediated inflammation. FASEB J. 2006, 20, 2118-2120. [CrossRef] [PubMed]

16. Lee, M.; Schwab, C.; Yu, S.; McGeer, E.; McGeer, P.L. Astrocytes produce the antiinflammatory and neuroprotective agent hydrogen sulfide. Neurobiol. Aging 2009, 30, 1523-1534. [CrossRef] [PubMed]

17. Bos, E.M.; Leuvenink, H.G.D.; Snijder, P.M.; Kloosterhuis, N.J.; Hillebrands, J.-L.; Leemans, J.C.; Florquin, S.; van Goor, H. Hydrogen sulfide-induced hypometabolism prevents renal ischemia/reperfusion injury. J. Am. Soc. Nephrol. 2009, 20, 1901-1905. [CrossRef] [PubMed]

18. Stipanuk, M.H.; Beck, P.W. Characterization of the enzymic capacity for cysteine desulphhydration in liver and kidney of the rat. Biochem. J. 1982, 206, 267-277. [CrossRef]

19. Ahmad, A.; Sattar, M.A.; Rathore, H.A.; Khan, S.A.; Lazhari, M.; Afzal, S.; Hashmi, F.; Abdullah, N.A.; Johns, E.J. A critical review of pharmacological significance of Hydrogen Sulfide in hypertension. Indian J. Pharmacol. 2015, 47, 243.

20. Moore, P.K.; Bhatia, M.; Moochhala, S. Hydrogen sulfide: From the smell of the past to the mediator of the future? Trends Pharmacol. Sci. 2003, 24, 609-611. [CrossRef]

21. Shibuya, N.; Mikami, Y.; Kimura, Y.; Nagahara, N.; Kimura, H. Vascular endothelium expresses 3-mercaptopyruvate sulfurtransferase and produces hydrogen sulfide. J. Biochem. 2009, 146, 623-626. [CrossRef]

22. Cheng, Y.; Ndisang, J.F.; Tang, G.; Cao, K.; Wang, R. Hydrogen sulfide-induced relaxation of resistance mesenteric artery beds of rats. Am. J. Physiol. Heart Circ. Physiol. 2004, 287, H2316-H2323. [CrossRef] [PubMed]

23. Webb, G.D.; Lim, L.H.; Oh, V.M.; Yeo, S.B.; Cheong, Y.P.; Ali, M.Y.; El Oakley, R.; Lee, C.N.; Wong, P.S.; Caleb, M.G. Contractile and vasorelaxant effects of hydrogen sulfide and its biosynthesis in the human internal mammary artery. J. Pharmacol. Exp. Ther. 2008, 324, 876-882. [CrossRef] [PubMed]

24. Al-Magableh, M.R.; Hart, J.L. Mechanism of vasorelaxation and role of endogenous hydrogen sulfide production in mouse aorta. Naunyn-Schmiedeberg's Arch. Pharmacol. 2011, 383, 403-413. [CrossRef] [PubMed]

25. Ali, M.; Ping, C.; Mok, Y.Y.; Ling, L.; Whiteman, M.; Bhatia, M.; Moore, P. Regulation of vascular nitric oxide in vitro and in vivo; A new role for endogenous hydrogen sulphide? Br. J. Pharmacol. 2006, 149, 625-634. [CrossRef] [PubMed]

26. Yang, G.; Wu, L.; Jiang, B.; Yang, W.; Qi, J.; Cao, K.; Meng, Q.; Mustafa, A.K.; Mu, W.; Zhang, S. H2S as a physiologic vasorelaxant: Hypertension in mice with deletion of cystathionine $\gamma$-lyase. Science 2008, 322, 587-590. [CrossRef]

27. Zhong, G.; Chen, F.; Cheng, Y.; Tang, C.; Du, J. The role of hydrogen sulfide generation in the pathogenesis of hypertension in rats induced by inhibition of nitric oxide synthase. J. Hypertens. 2003, 21, 1879-1885. [CrossRef]

28. Muzaffar, S.; Shukla, N.; Bond, M.; Newby, A.C.; Angelini, G.D.; Sparatore, A.; Del Soldato, P.; Jeremy, J.Y. Exogenous hydrogen sulfide inhibits superoxide formation, NOX-1 expression and Rac1 activity in human vascular smooth muscle cells. J. Vasc. Res. 2008, 45, 521-528. [CrossRef]

29. Suzuki, K.; Olah, G.; Modis, K.; Coletta, C.; Kulp, G.; Gerö, D.; Szoleczky, P.; Chang, T.; Zhou, Z.; Wu, L. Hydrogen sulfide replacement therapy protects the vascular endothelium in hyperglycemia by preserving mitochondrial function. Proc. Natl. Acad. Sci. USA 2011, 108, 13829-13834. [CrossRef]

30. Yang, C.; Yang, Z.; Zhang, M.; Dong, Q.; Wang, X.; Lan, A.; Zeng, F.; Chen, P.; Wang, C.; Feng, J. Hydrogen sulfide protects against chemical hypoxia-induced cytotoxicity and inflammation in HaCaT cells through inhibition of ROS/NF- $\mathrm{B} / \mathrm{COX}-2$ pathway. PLoS ONE 2011, 6, e21971. [CrossRef]

31. Aziz, N.M.; Elbassuoni, E.A.; Kamel, M.Y.; Ahmed, S.M. Hydrogen sulfide renal protective effects: Possible link between hydrogen sulfide and endogenous carbon monoxide in a rat model of renal injury. Cell Stress Chaperones 2020, 25, $211-221$. [CrossRef] [PubMed]

32. Tripatara, P.; Patel, N.S.; Collino, M.; Gallicchio, M.; Kieswich, J.; Castiglia, S.; Benetti, E.; Stewart, K.N.; Brown, P.A.; Yaqoob, M.M. Generation of endogenous hydrogen sulfide by cystathionine $\gamma$-lyase limits renal ischemia/reperfusion injury and dysfunction. Lab. Investig. 2008, 88, 1038-1048. [CrossRef] [PubMed]

33. Lobb, I.; Zhu, J.; Liu, W.; Haig, A.; Lan, Z.; Sener, A. Hydrogen sulfide treatment ameliorates long-term renal dysfunction resulting from prolonged warm renal ischemia-reperfusion injury. Can. Urol. Assoc. J. 2014, 8, E413. [CrossRef]

34. Hosgood, S.; Nicholson, M. Hydrogen sulphide ameliorates ischaemia-reperfusion injury in an experimental model of non-heartbeating donor kidney transplantation. Br. J. Surg. 2010, 97, 202-209. [CrossRef]

35. Lobb, I.; Mok, A.; Lan, Z.; Liu, W.; Garcia, B.; Sener, A. Supplemental hydrogen sulphide protects transplant kidney function and prolongs recipient survival after prolonged cold ischaemia-reperfusion injury by mitigating renal graft apoptosis and inflammation. BJU Int. 2012, 110, E1187-E1195. [CrossRef] 
36. Niu, X.; Smith, C.W.; Kubes, P. Intracellular oxidative stress induced by nitric oxide synthesis inhibition increases endothelial cell adhesion to neutrophils. Circ. Res. 1994, 74, 1133-1140. [CrossRef]

37. Kurose, I.; Wolf, R.; Grisham, M.B.; Aw, T.Y.; Specian, R.D.; Granger, D.N. Microvascular responses to inhibition of nitric oxide production role of active oxidants. Circ. Res. 1995, 76, 30-39. [CrossRef] [PubMed]

38. Afkir, S.; Nguelefack, T.B.; Aziz, M.; Zoheir, J.; Cuisinaud, G.; Bnouham, M.; Mekhfi, H.; Legssyer, A.; Lahlou, S.; Ziyyat, A. Arbutus unedo prevents cardiovascular and morphological alterations in L-NAME-induced hypertensive rats: Part I: Cardiovascular and renal hemodynamic effects of Arbutus unedo in L-NAME-induced hypertensive rats. J. Ethnopharmacol. 2008, 116, 288-295. [CrossRef]

39. Saravanakumar, M.; Raja, B. Veratric acid, a phenolic acid attenuates blood pressure and oxidative stress in L-NAME induced hypertensive rats. Eur. J. Pharmacol. 2011, 671, 87-94. [CrossRef] [PubMed]

40. Yan, H.; Du, J.; Tang, C. The possible role of hydrogen sulfide on the pathogenesis of spontaneous hypertension in rats. Biochem. Biophys. Res. Commun. 2004, 313, 22-27. [CrossRef]

41. Ahmad, A.; Sattar, M.A.; Azam, M.; Abdulla, M.H.; Khan, S.A.; Hashmi, F.; Abdullah, N.A.; Johns, E.J. Cystathione gamma lyase/Hydrogen Sulphide Pathway Up Regulation Enhances the Responsiveness of $\alpha 1 \mathrm{~A}$ and $\alpha 1 \mathrm{~B}$-Adrenoreceptors in the Kidney of Rats with Left Ventricular Hypertrophy. PLoS ONE 2016, 11, e0154995. [CrossRef]

42. Ahmad, A.; Sattar, M.Z.; Rathore, H.A.; Akhtar, S.; Khan, M.A.; Hashmi, F.; Abdullah, N.; Johns, E.J. Impact of isoprenaline and caffeine on development of left ventricular hypertrophy and renal hemodynamic in wistar kyoto rats. Measurements 2012, 76, 1015-1026.

43. Abdulla, M.H.; Sattar, M.A.; Abdullah, N.A.; Khan, M.A.H.; Abdallah, H.; Johns, E.J. Chronic treatment with losartan and carvedilol differentially modulates renal vascular responses to sympathomimetics compared to treatment with individual agents in normal Wistar Kyoto and spontaneously hypertensive rats. Eur. J. Pharmacol. 2009, 612, 69-74. [CrossRef]

44. Kiew, L.V.; Munavvar, A.S.; Law, C.H.; Azizan, A.N.; Nazarina, A.R.; Sidik, K.; Johns, E.J. Effect of antisense oligodeoxynucleotides for ICAM-1 on renal ischaemia-reperfusion injury in the anaesthetised rat. J. Physiol. 2004, 557, 981-989. [CrossRef] [PubMed]

45. Seeling, H.; Wust, H. Colorimetric method for determination of creatinine. Arztl. Lab 1969, 15, 34.

46. Ahmad, F.u.D.; Sattar, M.A.; Rathore, H.A.; Abdullah, M.H.; Tan, S.; Abdullah, N.A.; Johns, E.J. Exogenous hydrogen sulfide (H2S) reduces blood pressure and prevents the progression of diabetic nephropathy in spontaneously hypertensive rats. Ren. Fail. 2012, 34, 203-210. [CrossRef] [PubMed]

47. Jordan, J.E.; Zhao, Z.-Q.; Vinten-Johansen, J. The role of neutrophils in myocardial ischemia-reperfusion injury. Cardiovasc. Res. 1999, 43, 860-878. [CrossRef]

48. Jaeschke, H.; Bautista, A.; Spolarics, Z.; Spitzer, J. Superoxide generation by neutrophils and Kupffer cells during in vivo reperfusion after hepatic ischemia in rats. J. Leukoc. Biol. 1992, 52, 377-382. [CrossRef]

49. Johnson, K.J.; Weinberg, J.M. Postischemic renal injury due to oxygen radicals. Curr. Opin. Nephrol. Hypertens. 1993, 2, 625-635. [CrossRef]

50. Mehrabi, A.; Mood, Z.A.; Sadeghi, M.; Schmied, B.; Müller, S.; Welsch, T.; Kuttymuratov, G.; Wente, M.; Weitz, J.; Zeier, M. Thymoglobulin and ischemia reperfusion injury in kidney and liver transplantation. Nephrol. Dial. Transplant. 2007, 22, viii54-viii60. [CrossRef]

51. Weitz, J.; Koch, M.; Mehrabi, A.; Schemmer, P.; Zeier, M.; Beimler, J.; Büchler, M.; Schmidt, J. Living-donor kidney transplantation: Risks of the donor-benefits of the recipient. Clin. Transplant. 2006, 20, 13-16. [CrossRef]

52. Cerqueira, N.F.; Hussni, C.A.; Yoshida, W.B. Pathophysiology of mesenteric ischemia/reperfusion: A review. Acta Cir. Bras. 2005, 20, 336-343. [CrossRef]

53. Kim, S.-R.; Bae, Y.-H.; Bae, S.-K.; Choi, K.-S.; Yoon, K.-H.; Koo, T.H.; Jang, H.-O.; Yun, I.; Kim, K.-W.; Kwon, Y.-G. Visfatin enhances ICAM-1 and VCAM-1 expression through ROS-dependent NF-kB activation in endothelial cells. Biochim. Biophys. Acta (Bba)-Mol. Cell Res. 2008, 1783, 886-895. [CrossRef]

54. Khayyal, M.T.; El-Ghazaly, M.A.; Abdallah, D.M.; Nassar, N.N.; Okpanyi, S.N.; Kreuter, M.-H. Blood pressure lowering effect of an olive leaf extract (Olea europaea) in L-NAME induced hypertension in rats. Arzneim. Forsch. 2002, 52, 797-802.

55. Chia, T.Y.; Sattar, M.A.; Abdulla, M.H.; Rathore, H.A.; Ahmad, F.u.D.; Kaur, G.; Abdullah, N.A.; Johns, E.J. The effects of tempol on renal function and hemodynamics in cyclosporine-induced renal insufficiency rats. Ren. Fail. 2013, 35, 978-988. [CrossRef]

56. Zicha, J.; Dobesova, Z.; Kunes, J. Antihypertensive mechanisms of chronic captopril or N-acetylcysteine treatment in L-NAME hypertensive rats. Hypertens. Res. 2006, 29, 1021-1027. [CrossRef] [PubMed]

57. Rees, D.; Palmer, R.; Schulz, R.; Hodson, H.; Moncada, S. Characterization of three inhibitors of endothelial nitric oxide synthase in vitro and in vivo. Br. J. Pharmacol. 1990, 101, 746-752. [CrossRef] [PubMed]

58. Biancardi, V.C.; Bergamaschi, C.T.; Lopes, O.U.; Campos, R.R. Sympathetic activation in rats with L-NAME-induced hypertension. Braz. J. Med. Biol. Res. 2007, 40, 401-408. [CrossRef] [PubMed]

59. Zhao, W.; Zhang, J.; Lu, Y.; Wang, R. The vasorelaxant effect of H2S as a novel endogenous gaseous KATP channel opener. EMBO J. 2001, 20, 6008-6016. [CrossRef] [PubMed]

60. Xavier, F.; Magalhães, A.; Gontijo, J. Effect of inhibition of nitric oxide synthase on blood pressure and renal sodium handling in renal denervated rats. Braz. J. Med Biol. Res. 2000, 33, 347-354. [CrossRef]

61. Qiu, C.; Muchant, D.; Beierwaltes, W.H.; Racusen, L.; Baylis, C. Evolution of chronic nitric oxide inhibition hypertension Relationship to renal function. Hypertension 1998, 31, 21-26. [CrossRef] 
62. Snijder, P.M.; Frenay, A.-R.S.; Koning, A.M.; Bachtler, M.; Pasch, A.; Kwakernaak, A.J.; van den Berg, E.; Bos, E.M.; Hillebrands, J.-L.; Navis, G. Sodium thiosulfate attenuates angiotensin II-induced hypertension, proteinuria and renal damage. Nitric Oxide 2014, 42, 87-98. [CrossRef] [PubMed]

63. Kang, D.G.; Sohn, E.J.; Lee, Y.M.; Lee, A.S.; Han, J.H.; Kim, T.Y.; Lee, H.S. Effects of bulbus Fritillaria water extract on blood pressure and renal functions in the L-NAME-induced hypertensive rats. J. Ethnopharmacol. 2004, 91, 51-56. [CrossRef]

64. Wang, R. Two's company, three'sa crowd: Can H2S be the third endogenous gaseous transmitter? FASEB J. 2002, 16, 1792-1798. [CrossRef] [PubMed]

65. Wang, R. The gasotransmitter role of hydrogen sulfide. Antioxid. Redox Signal. 2003, 5, 493-501. [CrossRef] [PubMed]

66. Li, L.; Bhatia, M.; Zhu, Y.Z.; Zhu, Y.C.; Ramnath, R.D.; Wang, Z.J.; Anuar, F.B.M.; Whiteman, M.; Salto-Tellez, M.; Moore, P.K. Hydrogen sulfide is a novel mediator of lipopolysaccharide-induced inflammation in the mouse. FASEB J. 2005, 19, 1196-1198. [CrossRef]

67. Wang, K.; Ahmad, S.; Cai, M.; Rennie, J.; Fujisawa, T.; Crispi, F.; Baily, J.; Miller, M.R.; Cudmore, M.; Hadoke, P.W. Dysregulation of hydrogen sulfide producing enzyme cystathionine $\gamma$-lyase contributes to maternal hypertension and placental abnormalities in preeclampsia. Circulation 2013, 127, 2514-2522. [CrossRef]

68. Gao, Y.; Yao, X.; Zhang, Y.; Li, W.; Kang, K.; Sun, L.; Sun, X. The protective role of hydrogen sulfide in myocardial ischemiareperfusion-induced injury in diabetic rats. Int. J. Cardiol. 2011, 152, 177-183. [CrossRef]

69. Kang, K.; Zhao, M.; Jiang, H.; Tan, G.; Pan, S.; Sun, X. Role of hydrogen sulfide in hepatic ischemia-reperfusion-induced injury in rats. Liver Transplant. 2009, 15, 1306-1314. [CrossRef]

70. Xia, M.; Chen, L.; Muh, R.W.; Li, P.-L.; Li, N. Production and actions of hydrogen sulfide, a novel gaseous bioactive substance, in the kidneys. J. Pharmacol. Exp. Ther. 2009, 329, 1056-1062. [CrossRef]

71. Ahmad, A.; Sattar, M.A.; Rathore, H.A.; Abdulla, M.H.; Khan, S.A.; Azam, M.; Abdullah, N.A.; Johns, E.J. Up Regulation of cystathione $\gamma$ lyase and Hydrogen Sulphide in the Myocardium Inhibits the Progression of Isoproterenol-Caffeine Induced Left Ventricular Hypertrophy in Wistar Kyoto Rats. PLoS ONE 2016, 11, e0150137. [CrossRef] [PubMed]

72. Okusa, M.D.; Linden, J.; Macdonald, T.; Huang, L. Selective A2A adenosine receptor activation reduces ischemia-reperfusion injury in rat kidney. Am. J. Physiol.—Ren. Physiol. 1999, 277, F404-F412. [CrossRef] [PubMed]

73. Awad, A.S.; Ye, H.; Huang, L.; Li, L.; Foss, F.W.; Macdonald, T.L.; Lynch, K.R.; Okusa, M.D. Selective sphingosine 1-phosphate 1 receptor activation reduces ischemia-reperfusion injury in mouse kidney. Am. J. Physiol.—Ren. Physiol. 2006, 290, F1516-F1524. [CrossRef] [PubMed]

74. Ysebaert, D.K.; De Greef, K.E.; Vercauteren, S.R.; Ghielli, M.; Verpooten, G.A.; Eyskens, E.J.; De Broe, M.E. Identification and kinetics of leukocytes after severe ischaemia/reperfusion renal injury. Nephrol. Dial. Transplant. 2000, 15, 1562-1574. [CrossRef]

75. Kim, J.; Jang, H.-S.; Park, K.M. Reactive oxygen species generated by renal ischemia and reperfusion trigger protection against subsequent renal ischemia and reperfusion injury in mice. Am. J. Physiol.-Ren. Physiol. 2010, 298, F158-F166. [CrossRef]

76. Xu, Z.; Prathapasinghe, G.; Wu, N.; Hwang, S.-Y.; Siow, Y.L.; Karmin, O. Ischemia-reperfusion reduces cystathionine- $\beta$-synthasemediated hydrogen sulfide generation in the kidney. Am. J. Physiol.—Ren. Physiol. 2009, 297, F27-F35. [CrossRef]

77. Eschwege, P.; Paradis, V.; Conti, M.; Holstege, A.; Richet, F.; Deteve, J.; Menager, P.; Legrand, A.; Jardin, A.; Bedossa, P. In situ detection of lipid peroxidation by-products as markers of renal ischemia injuries in rat kidneys. J. Urol. 1999, 162, $553-557$. [CrossRef]

78. Patel, N.S.; Sharples, E.J.; Cuzzocrea, S.; Chatterjee, P.K.; Britti, D.; Yaqoob, M.M.; Thiemermann, C. Pretreatment with EPO reduces the injury and dysfunction caused by ischemia/reperfusion in the mouse kidney in vivo. Kidney Int. 2004, 66, 983-989. [CrossRef]

79. Irmak, M.K.; Koltuksuz, U.; Kutlu, N.O.; Yağmurca, M.; Özyurt, H.; Karaman, A.; Akyol, Ö. The effect of caffeic acid phenethyl ester on ischemia-reperfusion injury in comparison with $\alpha$-tocopherol in rat kidneys. Urol. Res. 2001, 29, 190-193. [CrossRef]

80. Sener, G.; Sehirli, A.Ö.; Keyer-Uysal, M.; Arbak, S.; Ersoy, Y.; Yeğen, B.Ç. The protective effect of melatonin on renal ischemiareperfusion injury in the rat. J. Pineal Res. 2002, 32, 120-126. [CrossRef]

81. Thiemermann, C.; Patel, N.S.; Kvale, E.O.; Cockerill, G.W.; Brown, P.A.; Stewart, K.N.; Cuzzocrea, S.; Britti, D.; Mota-Filipe, H.; Chatterjee, P.K. High density lipoprotein (HDL) reduces renal ischemia/reperfusion injury. J. Am. Soc. Nephrol. 2003, 14, 1833-1843. [CrossRef] [PubMed]

82. Şener, G.; Şehirli, Ö.; Velioğlu-Öğünç, A.; Çetinel, Ş.; Gedik, N.; Caner, M.; Sakarcan, A.; Yeğen, B.Ç. Montelukast protects against renal ischemia/reperfusion injury in rats. Pharmacol. Res. 2006, 54, 65-71. [CrossRef] [PubMed]

83. Hosseinzadeh, H.; Sadeghnia, H.R.; Ziaee, T.; Danaee, A. Protective effect of aqueous saffron extract (Crocus sativus L.) and crocin, its active constituent, on renal ischemia-reperfusion-induced oxidative damage in rats. J. Pharm. Pharm. Sci. 2005, 8 , 387-393. [PubMed]

84. Yan, S.-K.; Chang, T.; Wang, H.; Wu, L.; Wang, R.; Meng, Q.H. Effects of hydrogen sulfide on homocysteine-induced oxidative stress in vascular smooth muscle cells. Biochem. Biophys. Res. Commun. 2006, 351, 485-491. [CrossRef] [PubMed]

85. Whiteman, M.; Armstrong, J.S.; Chu, S.H.; Jia-Ling, S.; Wong, B.S.; Cheung, N.S.; Halliwell, B.; Moore, P.K. The novel neuromodulator hydrogen sulfide: An endogenous peroxynitrite 'scavenger'? J. Neurochem. 2004, 90, 765-768. [CrossRef]

86. Carden, D.L.; Smith, J.K.; Korthuis, R.J. Neutrophil-mediated microvascular dysfunction in postischemic canine skeletal muscle. Role of granulocyte adherence. Circ. Res. 1990, 66, 1436-1444. [CrossRef] 
87. Sekido, N.; Mukaida, N.; Harada, A.; Nakanishi, I.; Watanabe, Y.; Matsushima, K. Prevention of lung reperfusion injury in rabbits by a monoclonal antibody against interleukin-8. Nature 1993, 365, 654-657. [CrossRef]

88. Li, Z.; Nickkholgh, A.; Yi, X.; Bruns, H.; Gross, M.L.; Hoffmann, K.; Mohr, E.; Zorn, M.; Büchler, M.W.; Schemmer, P. Melatonin protects kidney grafts from ischemia/reperfusion injury through inhibition of NF-kB and apoptosis after experimental kidney transplantation. J. Pineal Res. 2009, 46, 365-372. [CrossRef]

89. Rusai, K.; Sollinger, D.; Baumann, M.; Wagner, B.; Strobl, M.; Schmaderer, C.; Roos, M.; Kirschning, C.; Heemann, U.; Lutz, J. Toll-like receptors 2 and 4 in renal ischemia/reperfusion injury. Pediatric Nephrol. 2010, 25, 853-860. [CrossRef]

90. Tuuminen, R.; Nykänen, A.; Saharinen, P.; Gautam, P.; Keränen, M.; Arnaudova, R.; Rouvinen, E.; Helin, H.; Tammi, R.; Rilla, K. Donor Simvastatin Treatment Prevents Ischemia-Reperfusion and Acute Kidney Injury by Preserving Microvascular Barrier Function. Am. J. Transplant. 2013, 13, 2019-2034. [CrossRef]

91. Jung, H.S.; Joo, J.-D.; Kim, D.-W.; In, J.H.; Roh, M.; Jeong, J.-T.; Noh, S.J.; Choi, J.W. Effect of milrinone on the inflammatory response and NF-kB activation in renal ischemia-reperfusion injury in mice. Korean J. Anesthesiol. 2014, 66, 136-142. [CrossRef]

92. Rogers, N.; Stephenson, M.; Kitching, A.; Horowitz, J.; Coates, P. Amelioration of renal ischaemia-reperfusion injury by liposomal delivery of curcumin to renal tubular epithelial and antigen-presenting cells. Br. J. Pharmacol. 2012, 166, 194-209. [CrossRef]

93. Seok, Y.M.; Kim, J.; Park, M.J.; Boo, Y.C.; Park, Y.K.; Park, K.M. Wen-pi-tang-Hab-Wu-ling-san attenuates kidney fibrosis induced by ischemia/reperfusion in mice. Phytother. Res. 2008, 22, 1057-1063. [CrossRef] [PubMed]

94. Schreck, R.; Albermann, K.; Baeuerle, P.A. Nuclear factor kB: An oxidative stress-responsive transcription factor of eukaryotic cells (a review). Free Radic. Res. Commun. 1992, 17, 221-237. [CrossRef] 